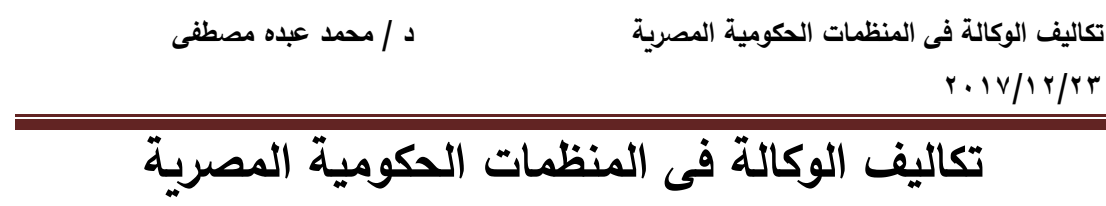

Agency Costs in the Egyptian Governmental Organizations

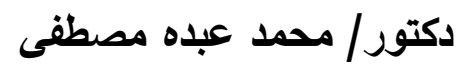

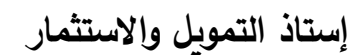

كلية التجارة جامعة عين شمس والأثمار

mohamedmoustafa7@hotmail.com

ملخص

Agency هذه الدراسة تتطلق من أن إفتراضات نظرية الوكالة

Teory التى تم تتميتها على الثركات المساهمة تتطبق على المنظمات الحكومية وشركات القطاع العام فى مصر ومن ثم فهذه المنظمات الحكومية تعانى من مشاكل

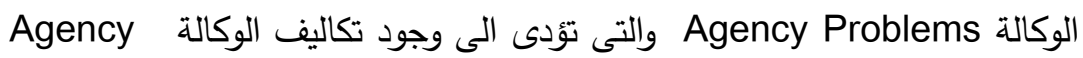
Costs والتى تمثل بدورها تآكل فى ثروة الثعب بإعتباره المالك الأصلى.

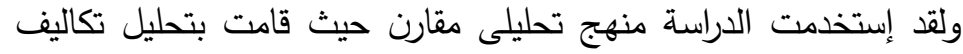

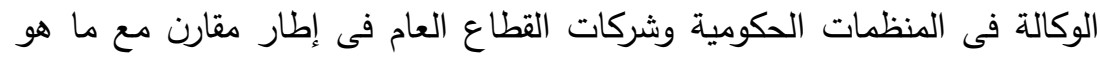

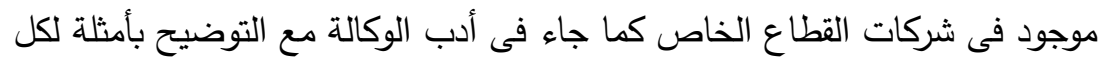

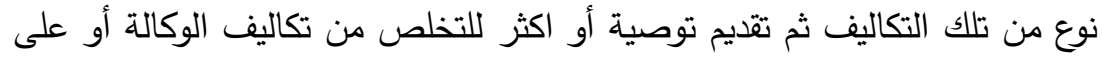
الأقل تخفيضها بما يساعدعلى الإصلاح الإقتصادى والإدارى لتلك المنظمات

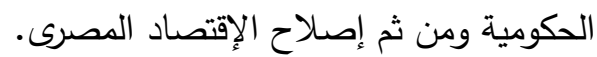

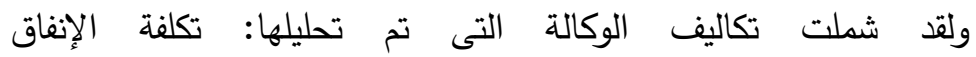

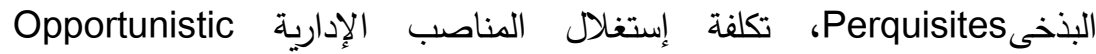
Behavior

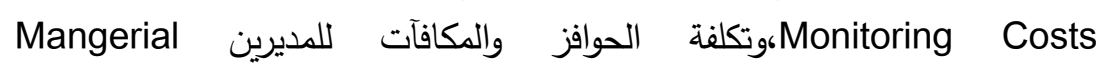


Compensation إختيار المديرين المناسبين بإعتبار أن ذلك يؤدى لزيادة جميع أنواع تكاليف الوكالة. مقدمة

الإقتصاد المصرى يعانى من مشكلات هيكلية ليست وليدة الوقت الحالى

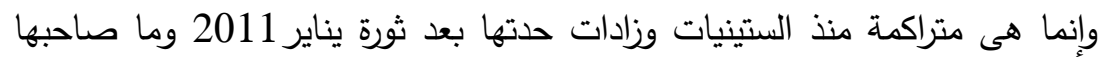

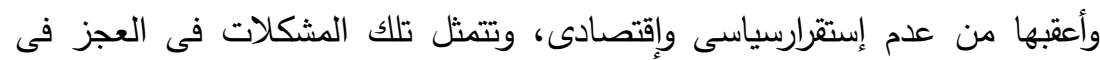
الموازنة العامة للدولة، وتزايد كل من الدين الداخلى والخارجى، والعجز فى الميزان التجارى نتيجة زيادة الواردات على الصادرات ومن ثم إنخفاض قيمة الجنيه المصرى لنه مقابل العملات الأجنبية، وضعف معدل النموالإقتصادى وإرتفاع نسبة البطالة

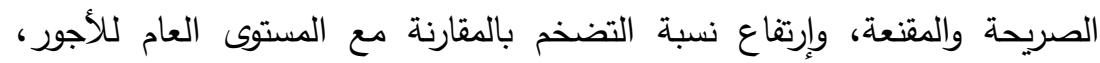
ووجود نسبة كبيرة من الإقتصاد غيرالرسمى والتفاوت الثديد فى الدخل.

ولقد شهدت السنوات القليلة الأخيرة تغييراً هيكلياً فى أساليب الإصلاح الإقتصادى وتمثل ذلك فى تغييرقانون العاملين فى الدولة والأجهزة الحكومية

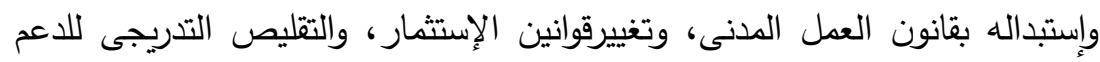
الموجه للسلع والخدمات مثل البنزين والكهرباء، ومحاولة توصيل الدعم لمستحقيه وتعويم الجنيه الدصرى مقابل العملات الأجنبية و رفع سعرالفائدة على الودائع بالجنيه المصرى وزيادة الإعتماد على الديون الداخلية من خلال أذون وسندات

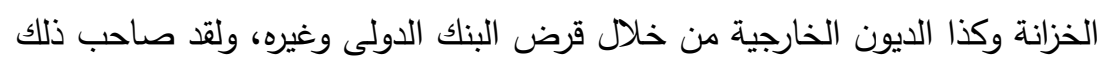
إرتفاع مستوى كل من إحتياطى النقد الأجنبى والتضخم بدرجة غير مسبوقة. 
إصلاح الإقصاد الدصرى يعتمد على الإصلاح الإقتصادى والإدارى لكل

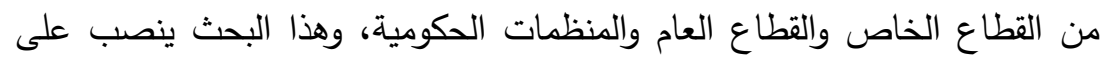

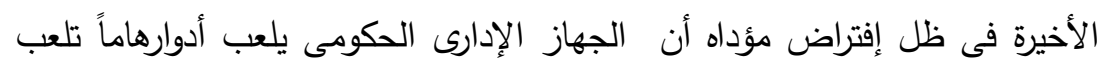

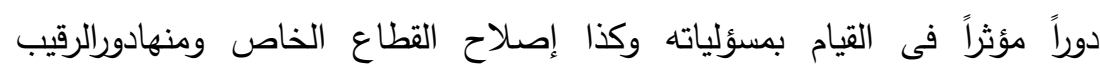
Regulator ودورالمسهل Facilitator، بجانب تقديم الخدمات الحكومية وإنتاج

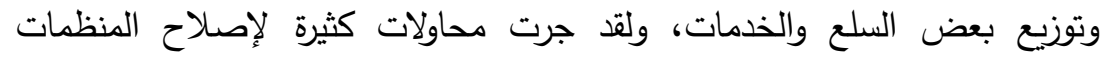
الحكومية وشركات القطاع العام فى مصر ولاتع ولق جرت

تهذف هذه الدراسات الى المساهمة فى محاولات الإصلاح الإقتصادى الإقى

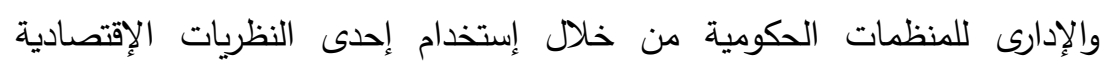

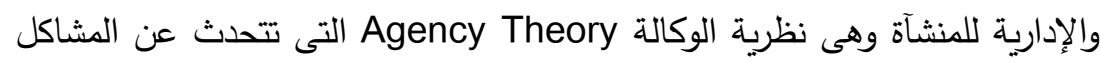

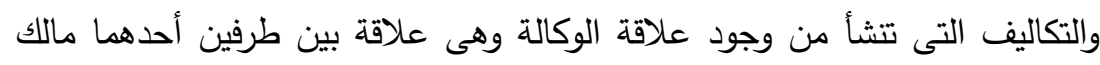

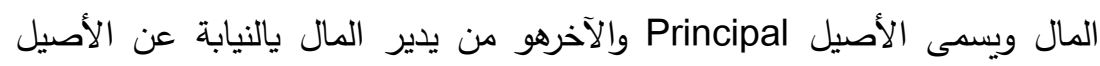

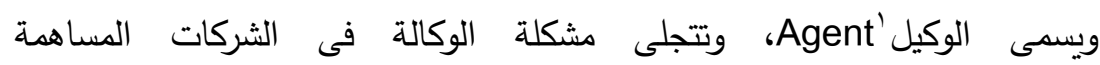

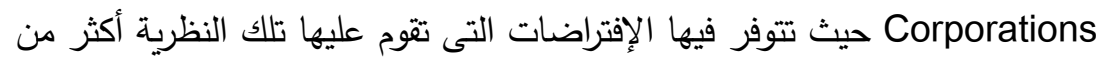
غيرها من الأشكال الأخرى للمنشآت والمنظمات. وأهم إفتراضات نظرية الوكالة و التى تعتبر بمثابة أسباب مشاكل الوكالة:

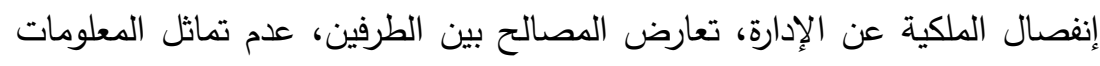
بين الطرفين، إختلاف الطرفين من حيث الإتجاهات نحو المخاطرة حيث أن النارئ 


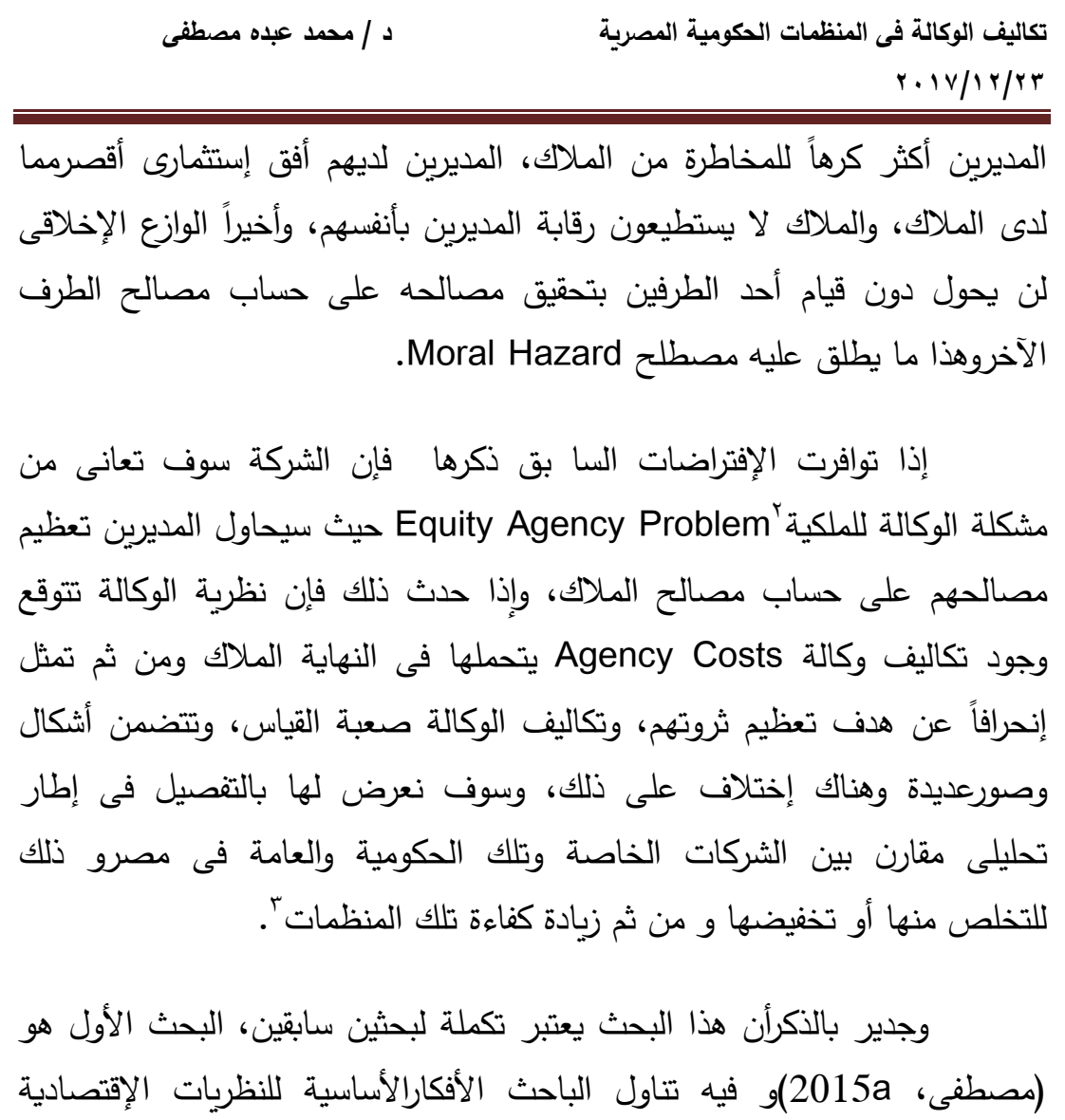

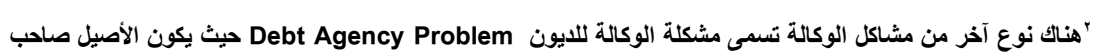

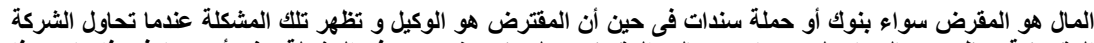

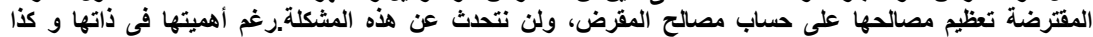
لتفاعلها مع مشكلة الوكالة للملكية.

Ross (1973), Jensen and Meckling (1976),Eisenhardt تفاصيل نظرية الوكالة يمكن أن تجدها فى (1989), Shleifer and Vishny (1997), Linder and Foss (2013), 
الرئيسية للمنشأة لأن فهم تلك النظريات وكذا الأسواق التى تعمل من خلالها

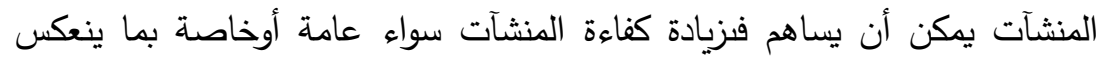
إيجاباً على الإقتصاد المصرى، وخلص الباحث الى إمكانية الاستفادة من كل نظرية،

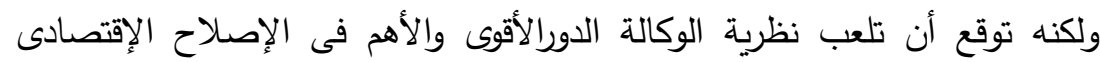
والإدارى المنظمات العامة الحكومية فى مصر.

وفى البحث الآخر (مصطفى، 2015b)توصلنا الى أن إفتراضات نظرية

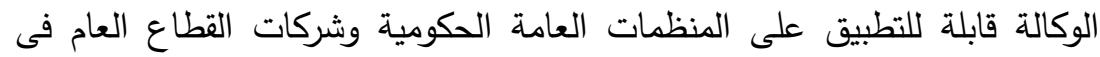

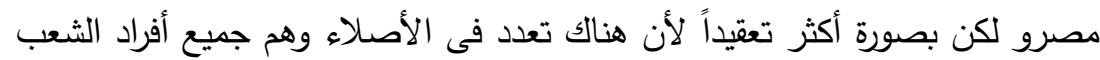
وتعدد فى الوكلاء وهم جميع الديرين فى المستويات المختلفة بدءاً بالوزراء

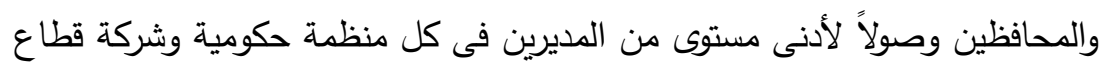

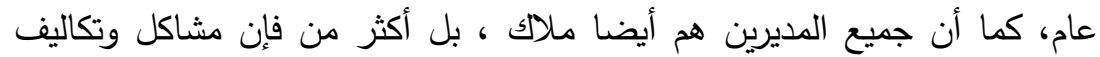

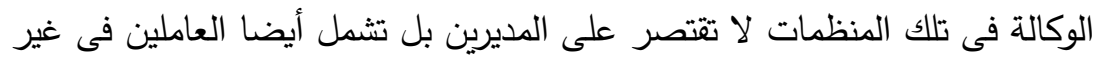
المناصب الإدارية و الذين هم أيضا ملاك و قوانين العمل تحميهم بدرجة كبيرة. وبالإضافة لكل ما سبق هناك رقباء متعددون على المديرين وهؤلاء يشملون الرقباء فى المستويات الإدارية المختلفة داخل كل منظمة ومن داخل الإهل الوزارة أو

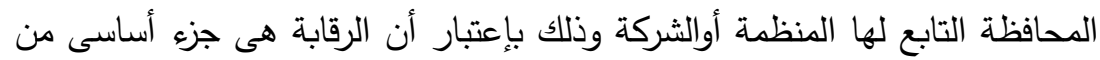

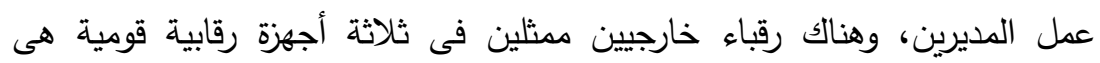
مجلس النواب وهيئة الرقابة الإدارية والجهازالمركزى للمحاسبات. ومن منطلق صلاحية نظرية الوكالة لأن تستخدم كإطارعام لفهم أداء تلك

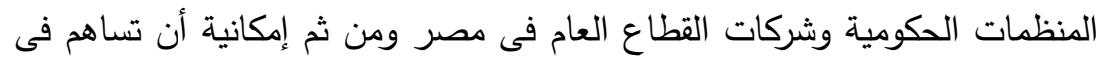


التخلص من أسباب ضعف الكفاءة الأقتصادية والإدارية، وبالتالى المساهمة فى في

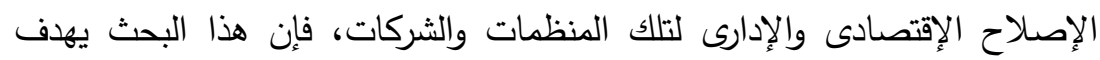
التى التعرف على تكاليف الوكالة Agency costs التى تترتب على مشاكل الوكالة Agency Problems بينها و بين شركات القطاع الخاص.

هذا مع العلم بأن تكاليف الوكالة يتحملها فى النهاية الملاك أى الثعب ومن ثم فهى تمثل إهداراً لثروة المجتمع، كما أنه من ناحية اخرى فإن تكاليف الوكالة تشمل التكاليف المرتبطة بطرق علاج مشكلة الوكالة والتى تدوربين الجزرة ممثلة فى لهى

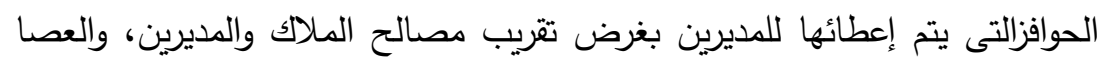
ممثلة فى الرقابة على المديرين وفرض عقوبات قد تصل الى حد إنهاء وظيفتهم فى

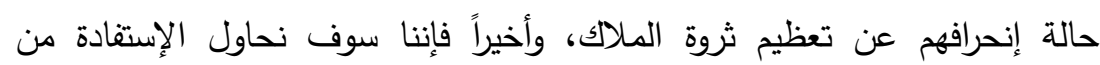
فكرتطبيقات حوكمة الشركات Corporate Governance بإعتبار أن أحد أهم أغراضه هوعلاج مشكلة الوكالة والحد من تكاليف الوكالة؛.

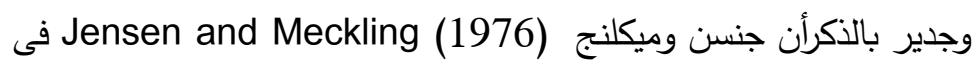
نموذجهما الشهير قسما تكاليف الوكالة الى الأنواع الثلاثة التالية:تكلفة رقابة الملاكل للمديرين Monitoring Costs، تكلفة التقييد Bonding Costs والخسارة المتبقية

"هذا منظور ضيق لمفهوم حوكمة الثركات من منظور نظرية الوكالة وعلم التمويل، لكن هناك مفهوم واسع لحوكمة

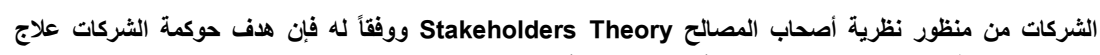

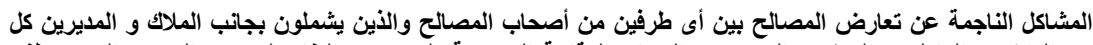

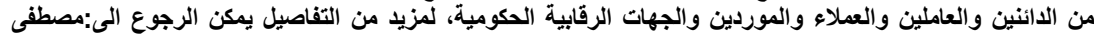

(2006) 
Residual loss، ولكننا سوف نتبنى هنا تقسيم آخر من واقع الدراسـات النظريـة

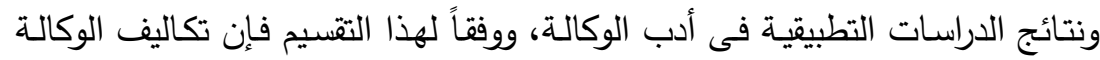
تشـمل:الإنفاق البـخى، تكـاليف إستغلال المنصـب، عدم أداء المديرين لواجباتهم،

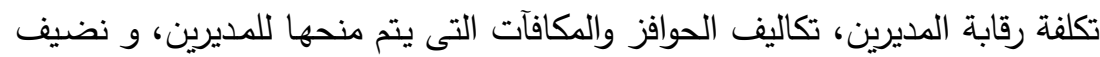
للأنواع السابقة تكاليف التسيب التى تتفرد بها المنظمات الحكومية وشركات القطاع العام.

وجديربالذكر أن أدب الوكالة يشير الى أن أحد أسباب مشكة الوكالة هو

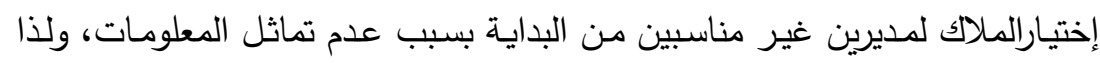

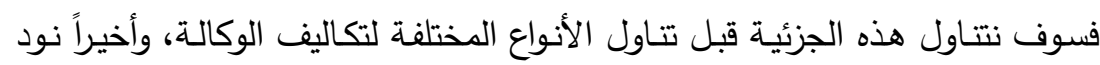

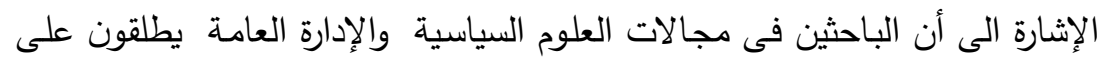

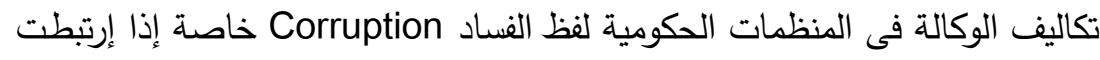
بالرشـوةB Bribery والإبتزاز Extortion وممارسـة الواسـطة والمحسـوبية للأصـدقاء Locatelli et al (2017), والمقربين Nepotism Cronyism

.Fjeldstad and Isaksen (2008) وقبل أن نبدأ فى عرض الدراسة قد يكون من المناسب توضيح نقطة هامة

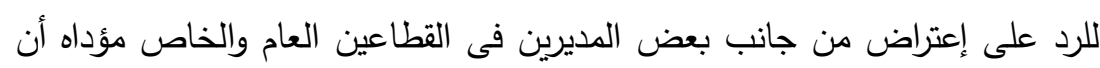

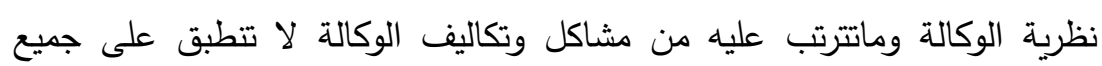

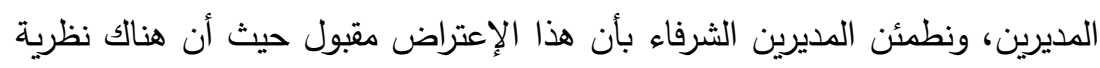
إدارية هى نظرية الضيافة Stewardship Theory لا ترى تعارض فى المصالح 


\begin{tabular}{|c|c|}
\hline دـ / محمد عبده مصطفى & 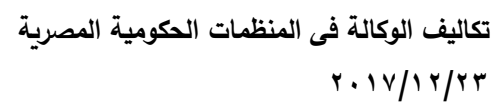 \\
\hline
\end{tabular}

وأخيراً هناك نقطة هامة نود الإشارة إليها فعندما ينتهى القارئ من هذه

الدراسة فربما يطالب بوجود بيانات وأرقام تدعم ما توصلنا إليه من تحليل، والباحث

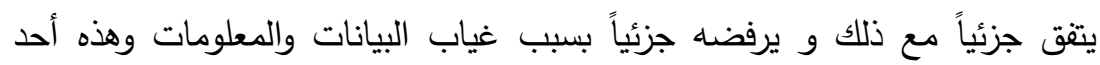

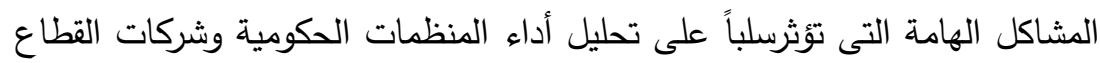
العام فى مصر والتى يرى الباحث أنها جزء من مشكلة الوكالة حيث أن المديرين المستفيدين من الأوضاع الحالية ليس من مصلحتهم وجود بيانات دقيقة عما يدور

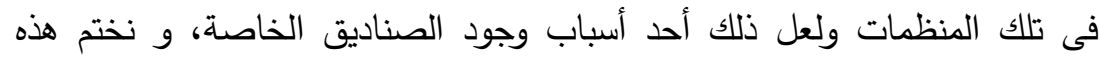

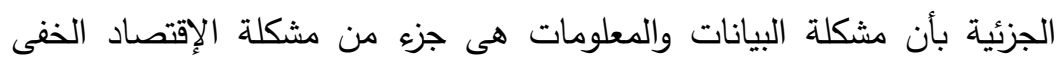
Hidden Economy أولاً/عدم إختيارالمدير (الوكيل) المناسب من قبل الملاك

\section{Choosing the Inappropriate Manager}

نظرية الوكالة ترى أن أحد أسباب مشاكل الوكالة ومن ثم تكاليف الوكالة هومشكلة الإختيارالعكسي Adverse Selection وذلك عندما ينخدع الأصيل

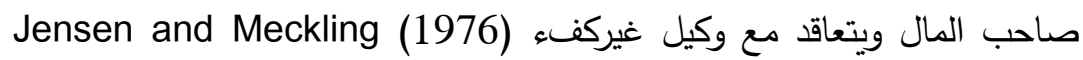

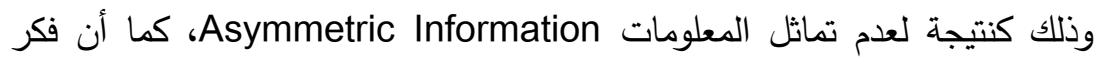
حوكمة الشركات أوضح لنا أن مما يساعد على وجود مشكلة إختيار المديرين غير المناسبين هو عدم كفاءة سوق العمل الإدارى Inefficient Managerial Labor 


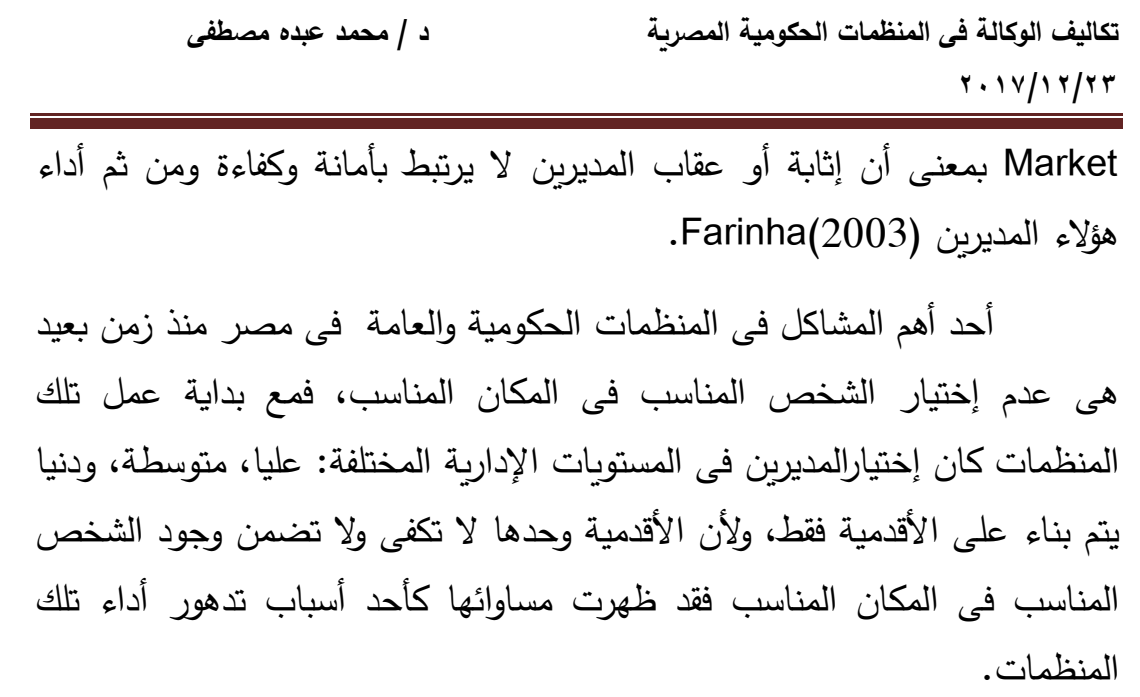

ثم حدثت تطورات إقتصادية وإجتماعية وسياسية أطاحت بالأقدية كأساس لإختيارالمديرين فى المنظمات الحكومية تدريجياً، فمع زيادة الإعتماد على القطاع ولئه الخاص منذ الثمانينات بدأت المقارنة بين الشركات الخاصة والمنظمات الحكومية العامة، ومع مزيد من تدهور الأخيرة وضعف الإهتمام بها ظهرت أصوات تتادى

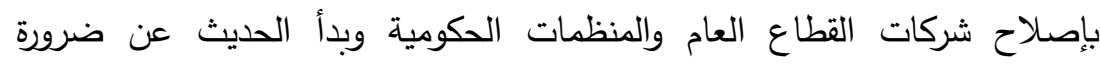
إستبدال الكفاءة بالأقدمية كأساس لإختيار المديرين.

ولكن لأسباب إجتماعية ممثلة فى قبول الثعب المصرى للمحسوبية والواسطة وكذا لاسباب سياسية يمكن تلخيصها فى الترويج لتوريث الحكم لجمال

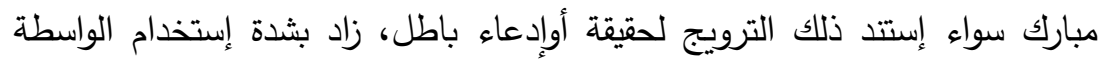

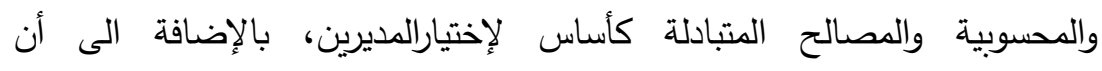

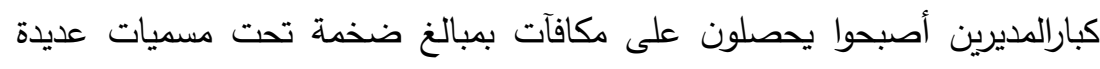
بعيداً عن الأجرالثابت الضعيف جداً.ولا غرو فى أننا لازلنا حتى اليوم فى نهاية 
2017 يتم إختيار المديرين فى أغلب الأحيان على أساس الواسطة والمحسوبية

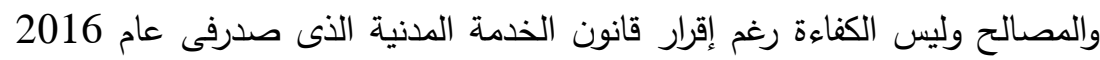

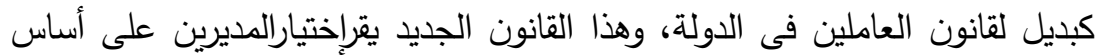

وهناك صور اخرى غير مباشرة أو مساعدة للخلل الموجود فى إختيار

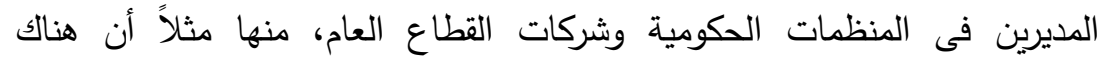

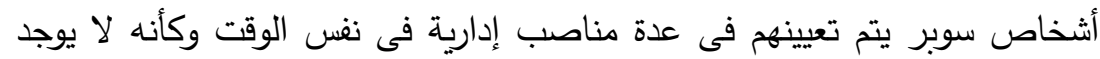
آخرين والأفضل أن نطبق آليات طبيعية تفرز مديرين من داخل المنظمة، وهناك صورة اخرى تتمثل بتعيين مستثارين فى مختلف الدجالات الفنية والإقتصادية

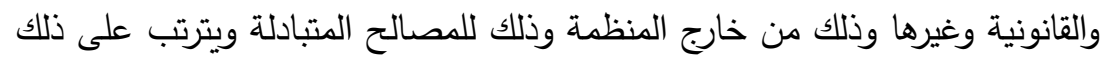

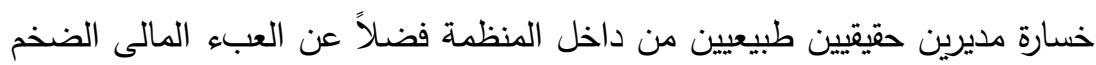

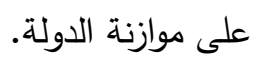

ويرى الباحث أنه لا يمكن إصلاح الدنظمات الحكومية والعامة إلا

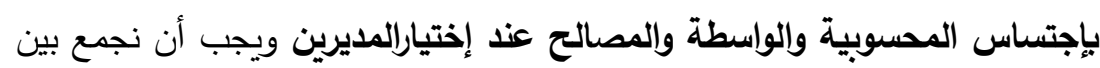
الأقدمية والكفاءة بعيداً عن المحسوبية التى يجب تجريمها فكم من كفاءات مخلصة التها تم تخطيها بسبب المحسوبية، والمجتمع لم يخسر فقط هذه الكفاء ات بل بل أيضا هذا كنا

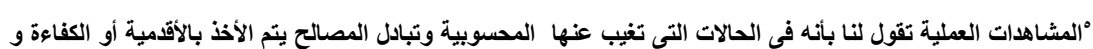

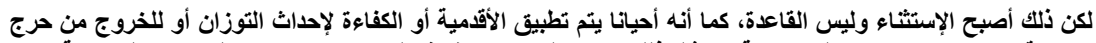

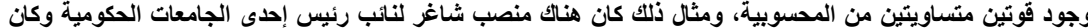

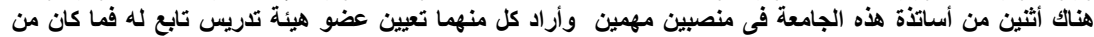
رئيس الجامعة إلا أن أتى بعضو هيئة تدريس تابع له للخروج من المأزق أو لإستثمار الموقف. 
التخطى الظالم يدمر النفوس النظيفة المخلصة وربما ينقلب بعضهم و يمارس دوراً

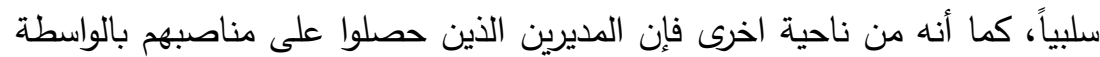
والمحسوبية لن يكون ولائهم إلا لمن أتى بهم فى المنصب كما أن ذلك يرسل الى الى

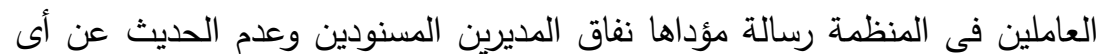

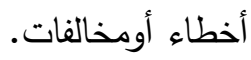

وحتى نجمع بين الأقدية والكفاءة يجب أولاً أن نحدد الأهداف والنتائج

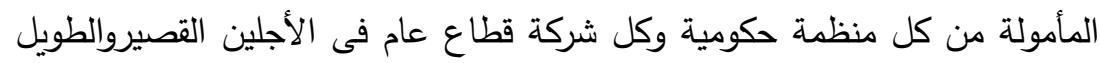
و ذلك بطريقة قابلة للقياس وتتقق مع السياسة العامة للدولة والتى تم وضعها بناء على إحتياجات ومطالب الشعب والتى يجب تحديدها بآليات ديمقراطية، ويتم

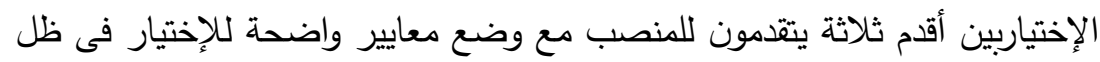

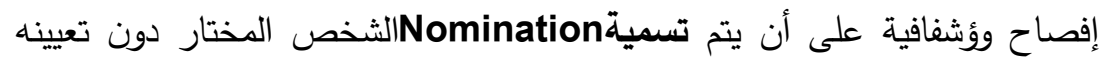
وإعطاء مهلة بسيطة ولتكن نصف شهر ليتقدم خلالها أى شخص لله إعتراض رسمى لئى لئه على المدير الذى تمت تسميته. وفى نفس الوقت نوصى أن تقدم الجهات الأمنية تقريرها عن المرشح دون

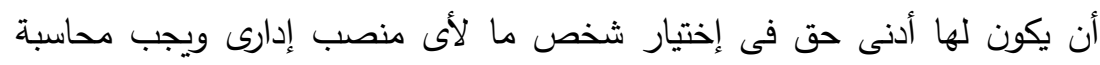
عضو الأجهزة الأمنية الذى يقدم إستعلام مغلوط أو كاذب للترويج لشخص لـإل لم يكن

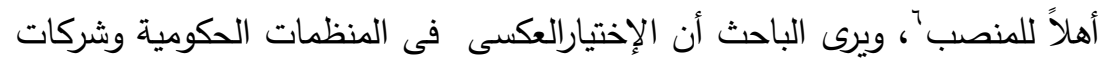

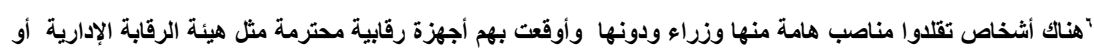

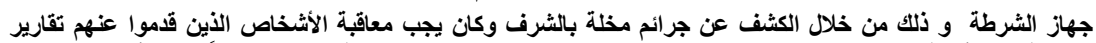

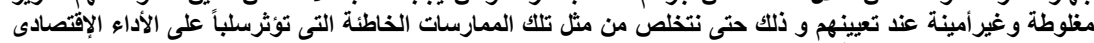

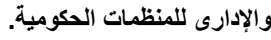




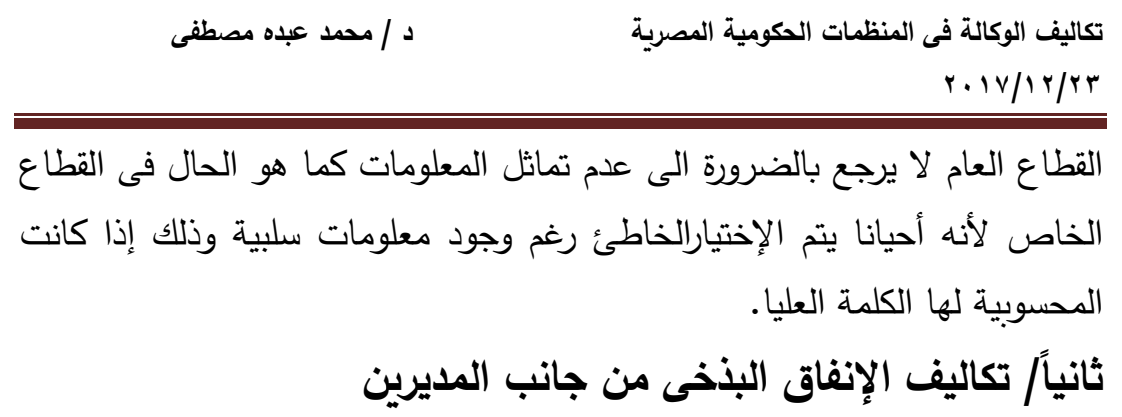

\section{On- the- Jop Perquisites}

قبل ظهور نظرية الوكالة فى شكلها الحديث تحدث علماء النظرية الإدارية

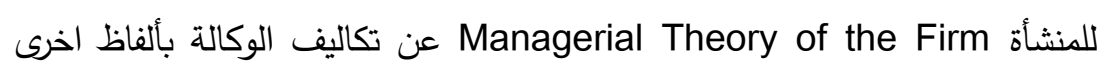
حيث أن وليامسون Williamson قدم مصطلح إنفراد الإدارة بالسيطرة

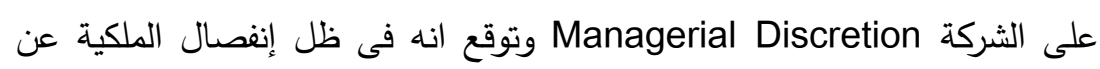

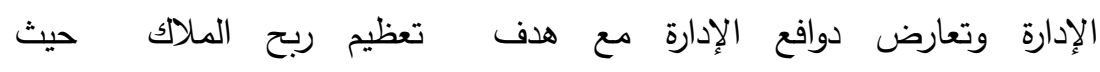

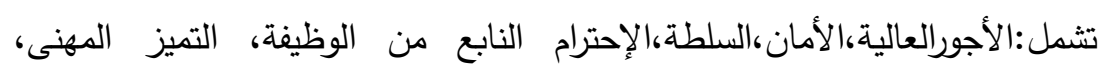

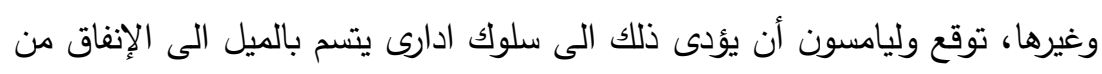

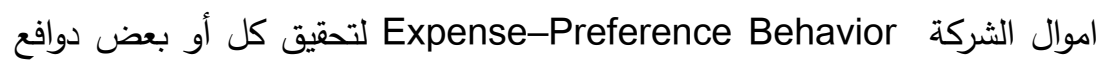
الادارة بعيدا عما إذا كان هذا الإنفاق يساهم فى تعظيم ربح الملاك. Jensen ثماءت نظرية الوكالة فى شكلها الحديث من خلال مقالة وتحدثت عن الإنفاق البذخى من جانب المديرين وهوعبارة عن منافع غير نقدية Non Pecuniary Benefits تحقق لهم إثباع دون أن

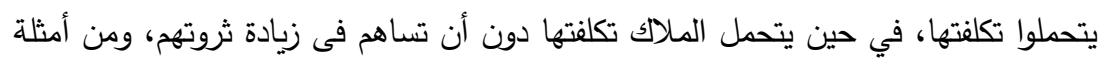

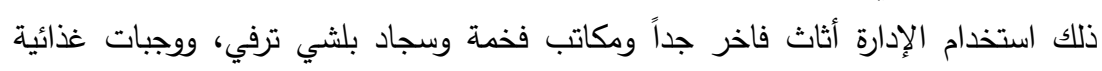

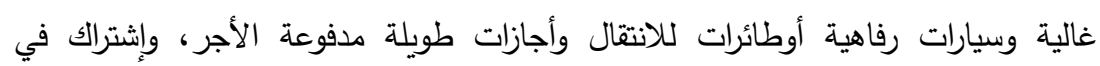


عضوية أندية غالية، وجدير بالذكر أن النظرية تتحدث عن الإنفاق البنخى لأن المديرين

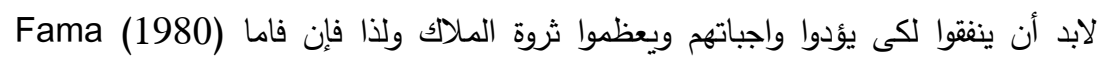

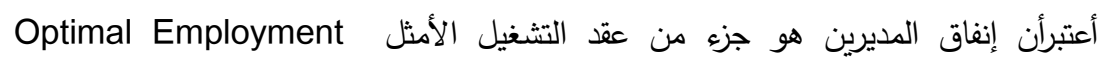
Contract

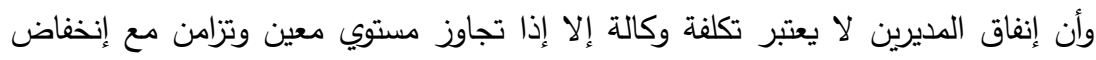

والباحث يرى أن هذا النوع من تكلفة الوكالة موجود وبشدة فى المنظمات الحكومية وشركات القطاع العام فى مصر ، ومن أهم أمثلته المبانى والأثاث الفاخروالسيارات

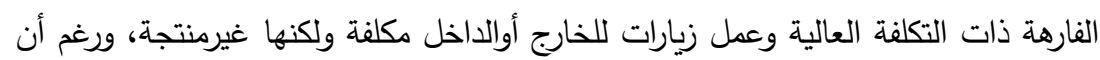

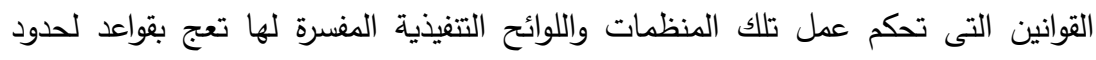

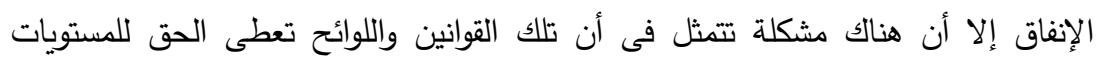

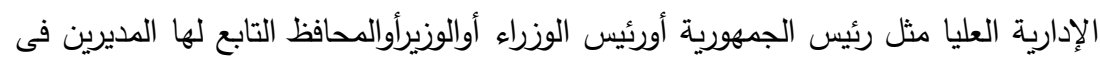
تقديم إستثناءات وحق حفظ المخالفات.

ومن ناحية أخرى فإنه رغم أن وزارة المالية والجهازالمركزى للمحاسبات يراجعان

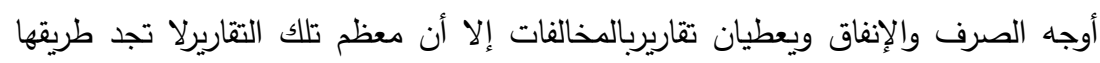

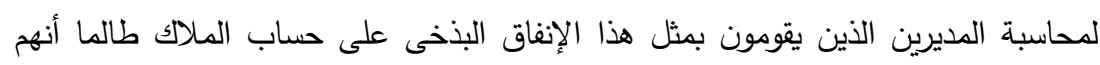

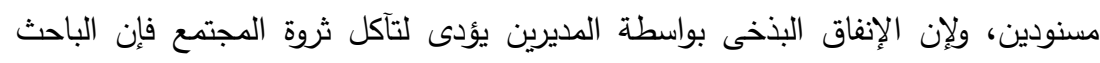
يوصى هنا بوضع حدود موضوعية لإنفاق المديرين وبتثديد العقوبات وتتفيذها دون إستثناءات، وكذلك نشرالمخالفات والعقوبات فى وسائل الإعلام وفى المنظمات التى تقع فيها

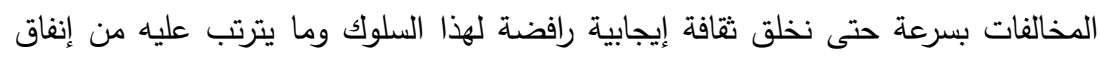
بذخى وذلك على مستوى الثعب ككل وعلى مستوى العاملين فى كل منظمة. 
ثالثاً تكاليف إستغلال المنصب من قبل المديرين

\section{Costs of Managerial Opportunistic Behavior}

السلوك الإنتهازى من جانب المديرين كما تحدث عنه علماء النظرية

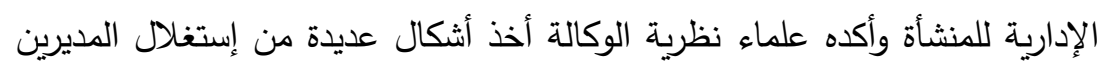

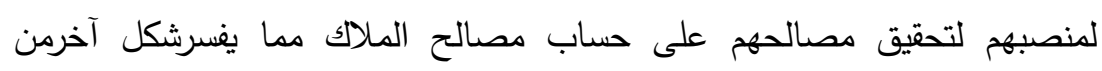
تكاليف الوكالة أثبتته الدراسات التطبيقية ومن ذلك: بيع أصول الشركة الي شركات

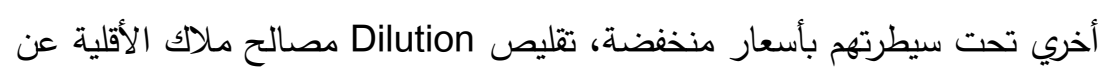

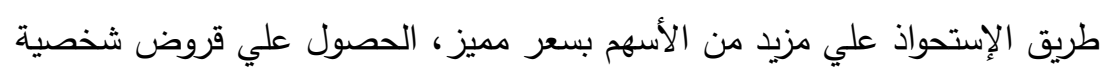

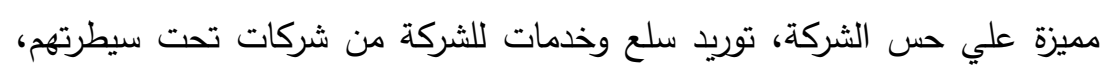

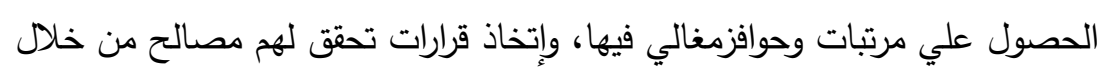

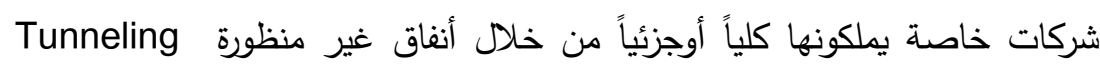

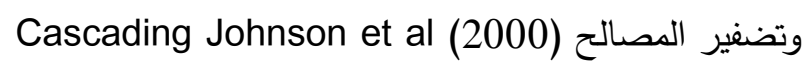
ويتوقع الباحث أن يوجد هذا الثكل من تكاليف الوكالة فى المنظمات

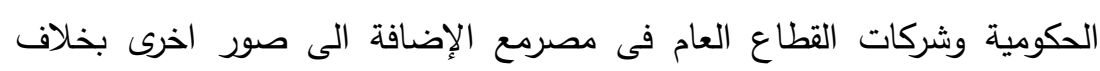

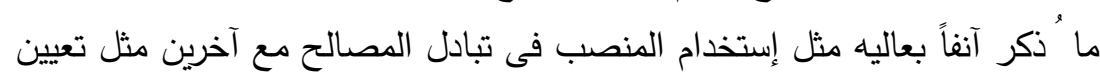

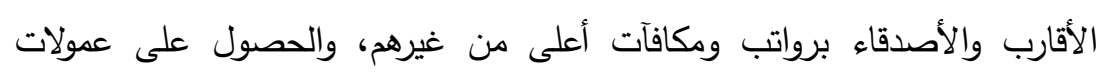

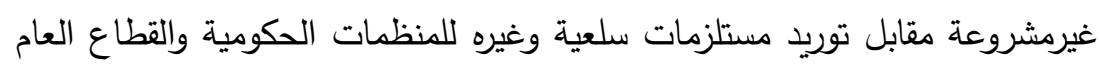

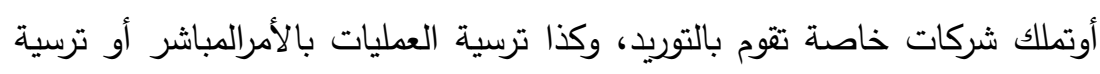

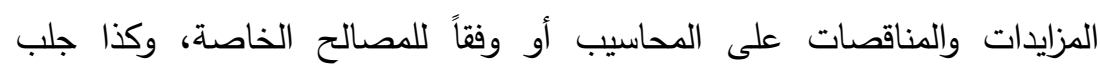




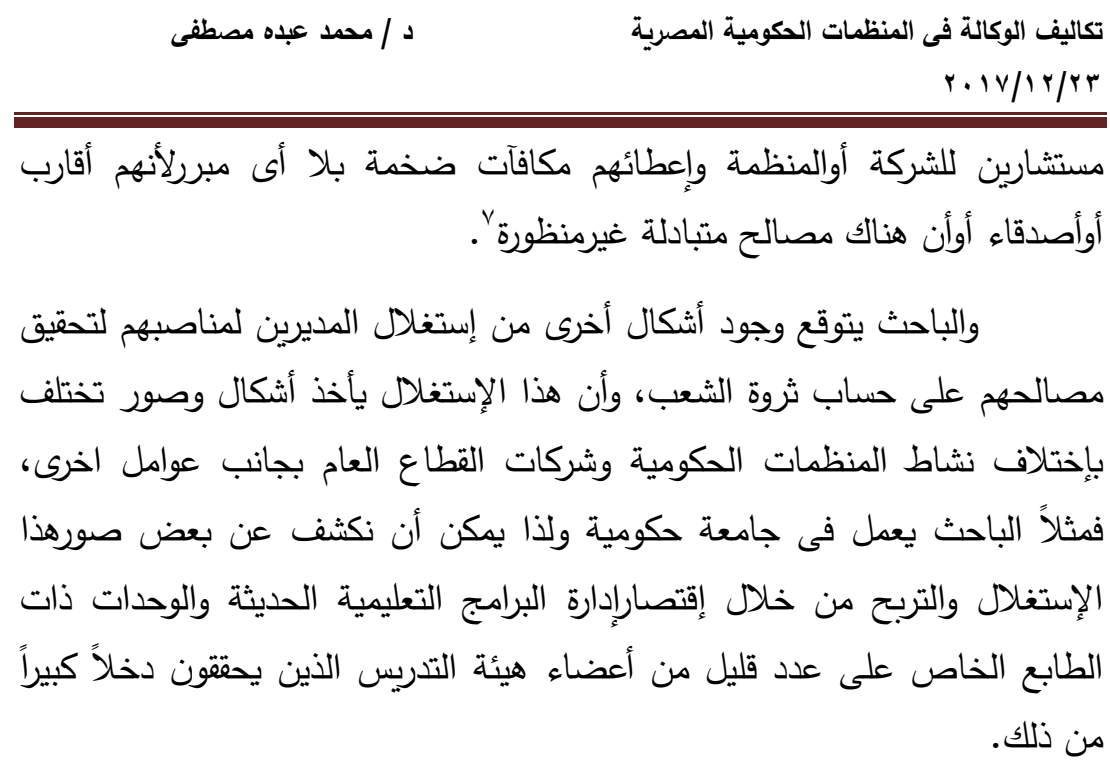

شكل آخر يتمثل فى إستغلال الوحدات ذات الطابع الخاص للتربح، فمثلاً

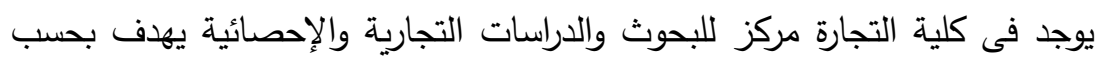
قانون إنشائه الى الربط بين الجامعات والصناعة (السوق) وتحقيق دخل من خلال

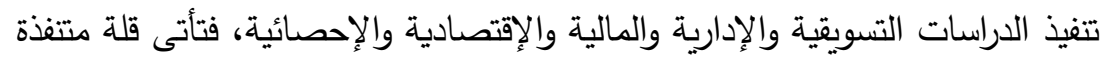

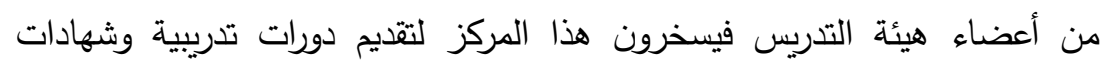

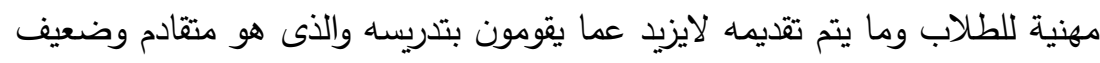
وغير متطورويحققون من وراء ذلك دخول ضخمة.

" هذا السلوك تمت ملاحظته من خلال قرارات الخصخصة بييع كل أو جزء من شركات القطاع العام بأقل من قيمتها وبثروط مجحفة بحيث تخسر الدولة إذا ما لجأت الى التحكيم. 
هذا السلوك فى المثال السابق لله تكلفة كبيرة وتداعيات خطيرة حيث يمنع

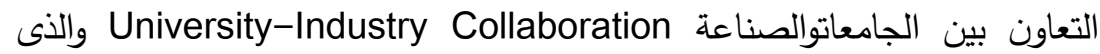
من خلاله يتم تحويل ما تتتجه الجامعة من معرفة Knowledge الى لى ماتى

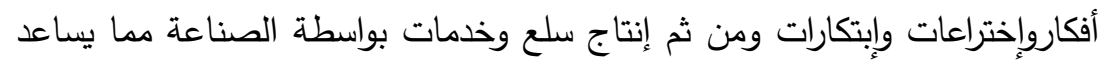
على إحداث التتمية والنموالإقتصاديين وإسعاد المجتمع، بدلاًا أن تقوم الدولة بإستيراد

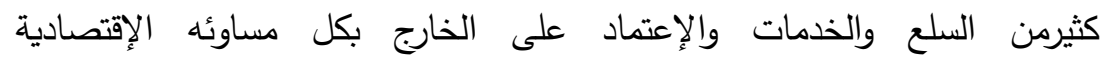

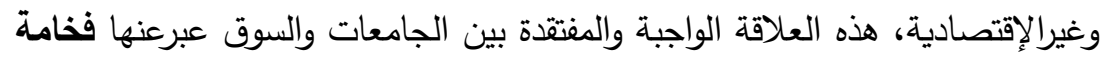
الرئيس/عبد الفتاح السيسى بكلمة بليغة فى حفل الإحتفال بعيد العلم فى أغسطس ولئ

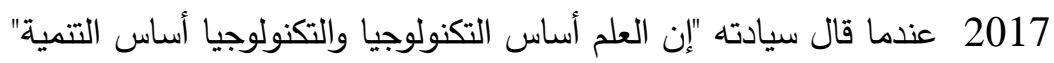
ولذا لابـد من اللجوء الى الشرفاء فى كل المنظمـات الحكوميـة وشركات

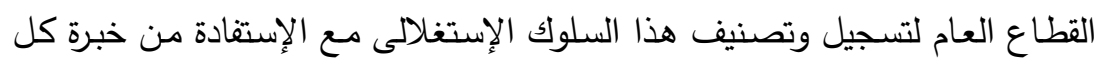

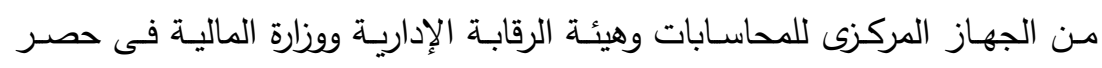

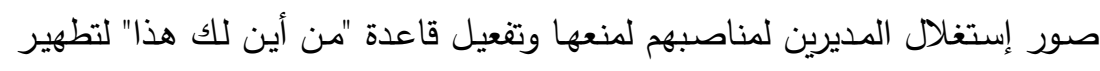

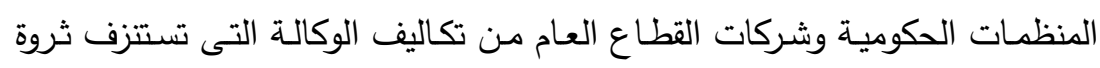

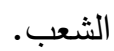

وفى هذا المقام يجدر بنا أن نشيرالى شكل آخر من تكاليف الوكالة فى المنظمات الحكومية وشركات القطاع العام حيث يقول Niskanen فى عمله تئه الرائد

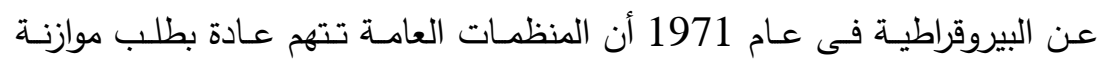

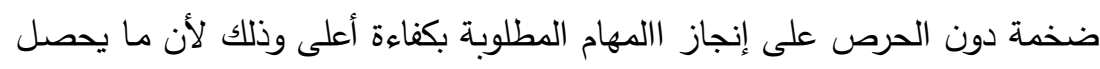

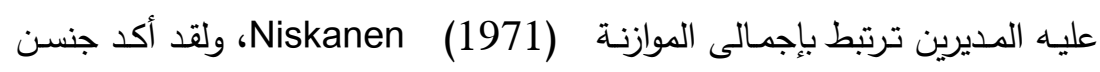


Budgeting ذلك من خلال لعب المديرين مباراة الميزانية Jensen (2003) Game

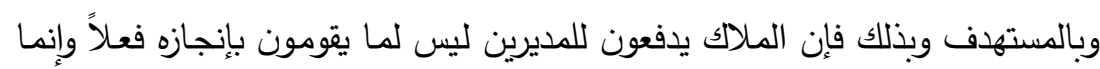

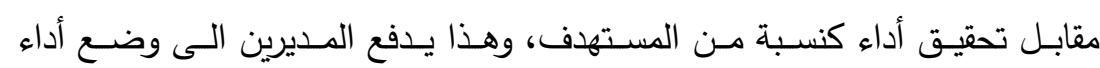

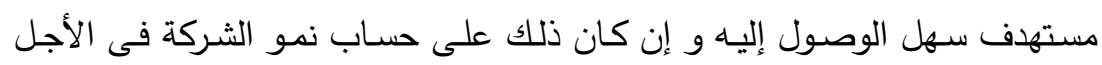

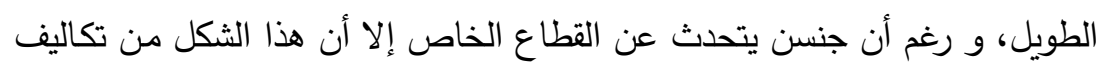
الوكالة موجود فى المنظمات الحكومية و شركات القطاع العام.

\section{رابعاً/ تكلفة عدم أداء المديرين للواجبات المنوطة بهم}

\section{Shirking}

المديرين الذين ليس لديهج وازع إخلاقى ويحصلون على أجور ثابتة ربها

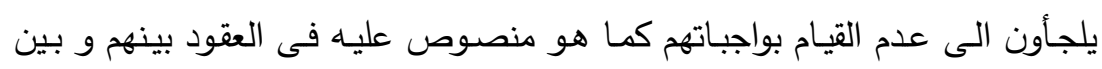

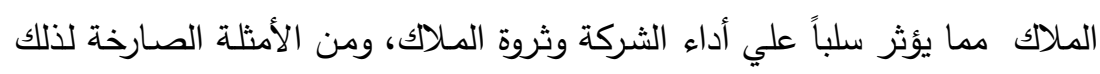

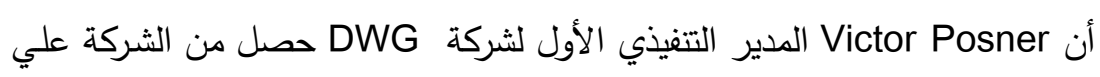

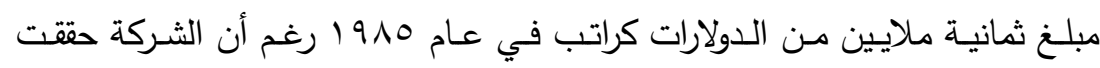

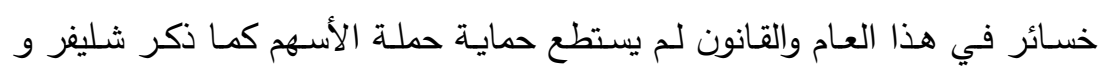

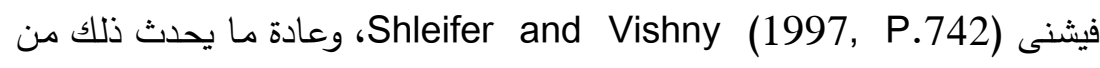
المديرين المتنفذين Entrenched Managers الذين يحصنون أنفسهم ضد الطرد رغم عدم كفاءتهم في إدارة الشركة. 
هذا النوع من تكاليف الوكالـة موجود في المنظمـات الحكوميـة وشـركات

القطاع العام فى مصرعلى مستوى كل من المديرين والعاملين سواء لغياب الوازع مهن

الإخلاقى مـن جانب من يحصلون على أكثرمن حقوقهم والمحصنين ضـد الطرد

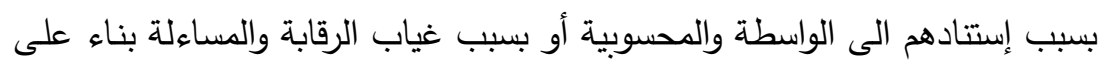

ومـن ناحيـة اخرى فقد يوجد هذا السـلوك مـن جانب المديرين والعـاملين

المغلوبين على أمرهم ويحصلون على أقل من حقوقهم، أوقد يحدث من جانب من هن هن

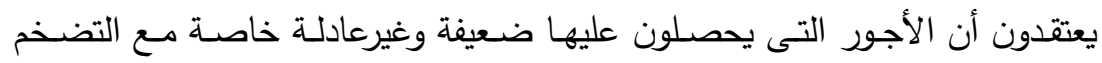

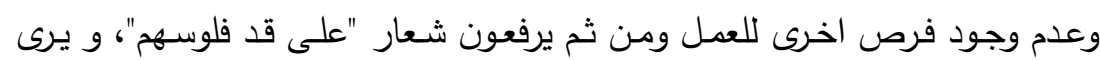

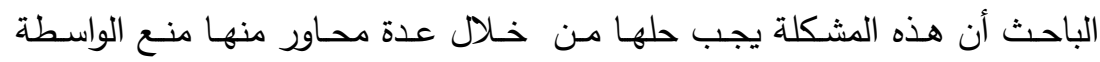
والمحسوبية والمساءلة بحسب النتائج، والعدالة بين جميع المديرين والعاملين، وكذا

تغيير نظام الأجور والحوافزعلى النحو الذى سيتم تفصيله فى النقطة التالية. خامساً تكلفة رقابة المديرين

\section{Monitoring Costs}

نظرية الوكالة تفترض عدم قدرة المـلاك على رقابة المديرين ومن ثم فأن

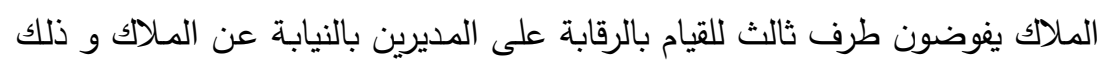

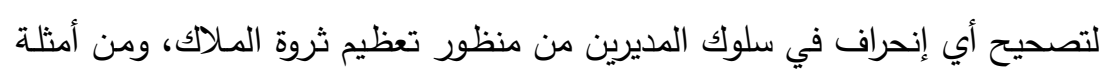

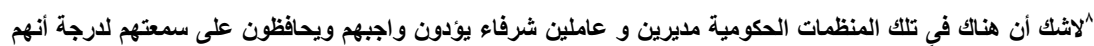

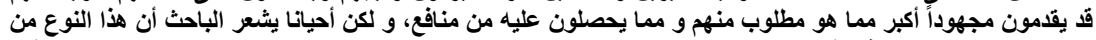

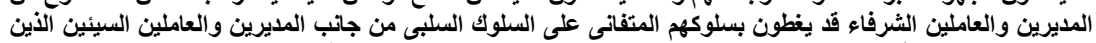

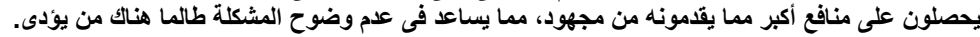


تكلفة رقابـة المديرين: المصـاريف التى يدفعها المـلاك للمراجع الخـارجى لحسابات

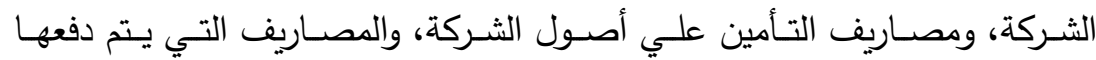

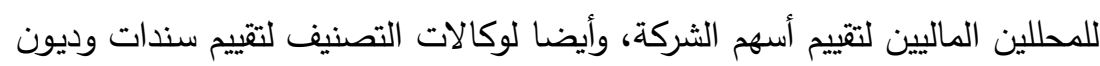

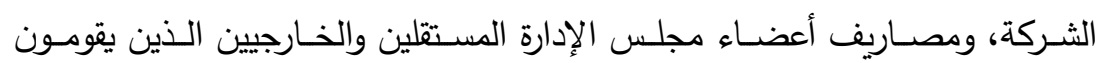
بالرقابة على مديرى الشركة(1976) Jensen and Meckling

و يرى الباحث أن تكاليف رقابة المديرين فى المنظمات الحكومية وشركات

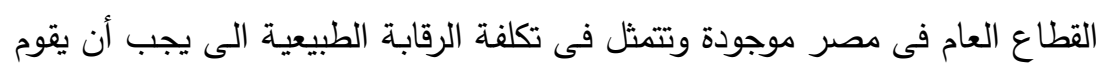
بها كل مستوى إدارى على مرؤسيه بحسب التسلسل التظظيمى فى الثركة والمنظمـة، بالإضـافة الى تكاليف كل من الجهاز المركزى للمحاسـابات وهيئة الرقابة الإداريـة بالإضـافة الى جزهما يحصل عليه أعضاء مجلس النواب لأن جزء من مسؤلياتهم

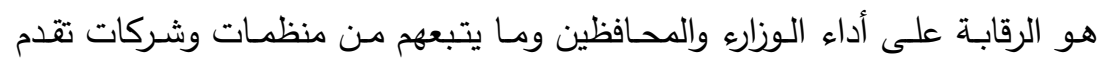

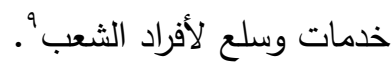

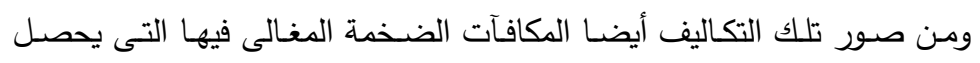

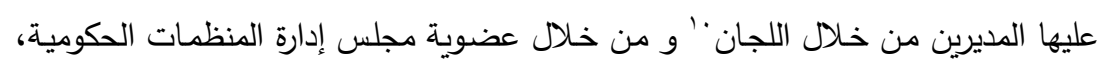

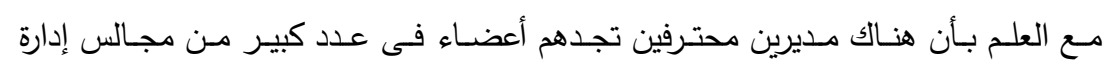

"من ضمن السلوكيات السلبية التى تزيد من تلك التكاليف أن تجد مثلاً وزيرأورئيس شركة أومنظمة حكومية يقوم بتعيين

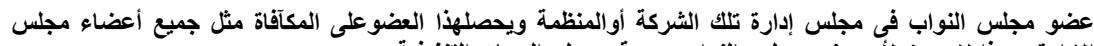
الإدارة، وهذا لا يجوز لأن عضو مجلس مجل النواب هو رقيب على الجهات التنفيذية.

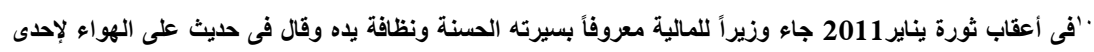

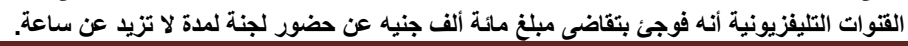


المنظمات الحكومية و يحصلون على المكافآت ومزايا أخرى دون أن يكون لهم دور ملموس

$$
\text { فى تحسين أداء المنظمات و حماية المال العام. }
$$

ويجب هنا أن نقيس تكاليف الرقابة ونقارنها بما تحققه من نفع يتمثل فى تقليل

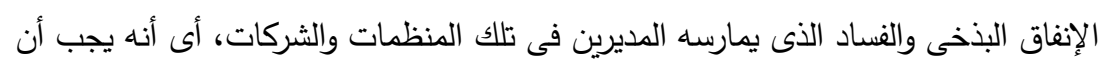

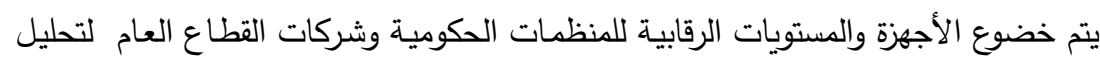

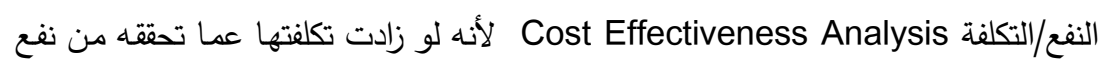
فإن تلك الزيادة تمثل تكلفة وكالة يتحملها الشعب، و يجب أيضا أن نأخذ بأفضل ممارسات

$$
\text { حوكمة الشركات فيما يتعلق بمجالس إدارات المنظمات و الشركات العامة. }
$$

ويود الباحث أن يشير الى نوع آخر من التكاليف المرتبط بالرقابة على المديرين

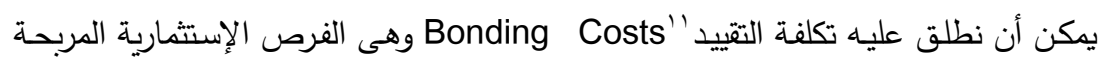

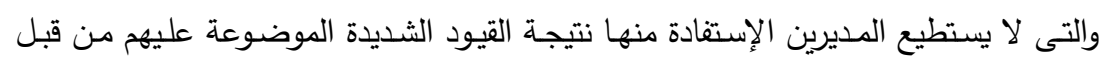

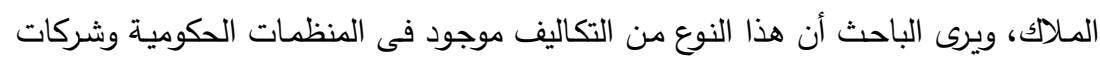

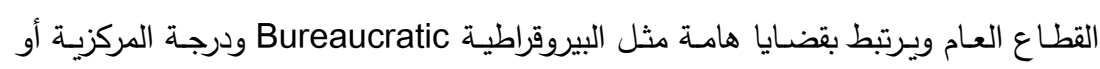

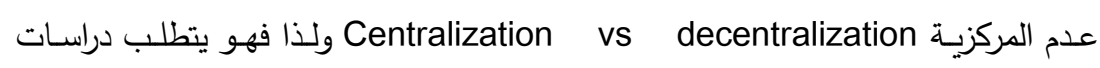

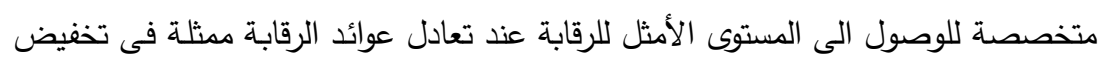

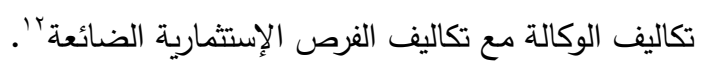

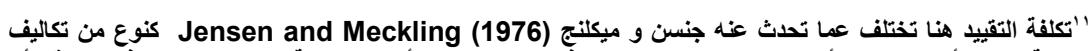

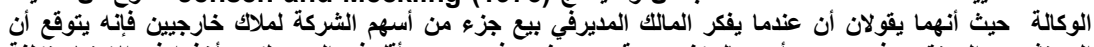

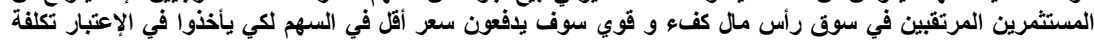

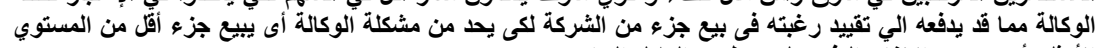

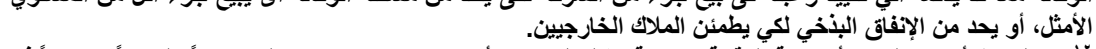

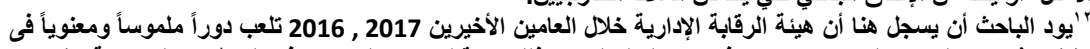

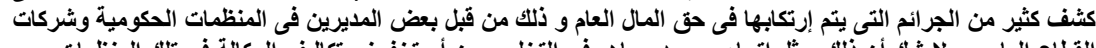

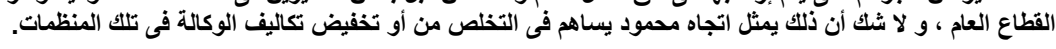




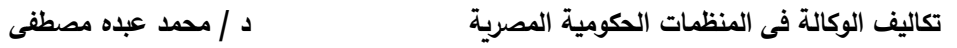 $r+1 \mathrm{r} / \mathrm{h} / \mathrm{rr}$ \\ سادساً/تكلفة الحوافز والمكافآت التى يحصل عليها المديرين \\ Managerial Compensation}

نظريـة الوكالة تقترح حل مشكلة الوكالة بتقريب مصالح كل من الملاك و المديرين

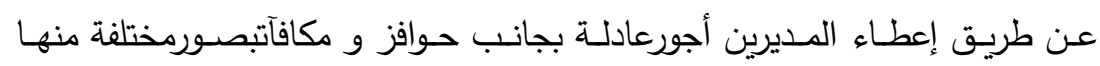

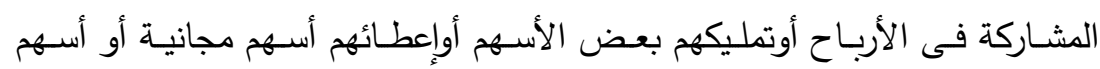
بأسعار أقل من القيمة السوقية على ألا يحق لهم بيع تلك الأسهم إلا إذا أرتقع سعرها الى مستوى معين Stock Options، ولكن نتائج كثيرمن الدراسات التطبيقية لم تؤيد العلاقة المتوقعة بين زيادة ما يحصل عليه المديرين من مكافآت وحوافز وبين تحسن

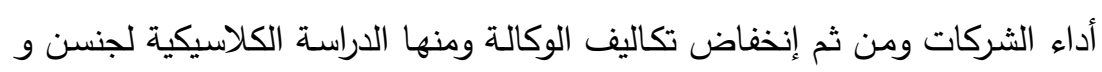
ميرفى (1990) Jensen and Murphy

هذه المشكلة وما يترتب عليها من تكاليف مهمة وموجودة فى المنظمات

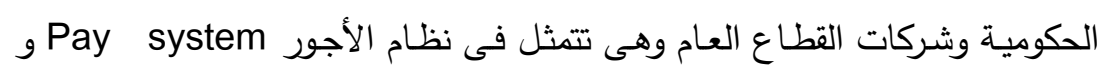

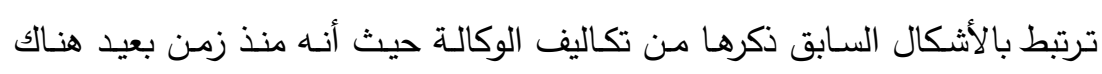

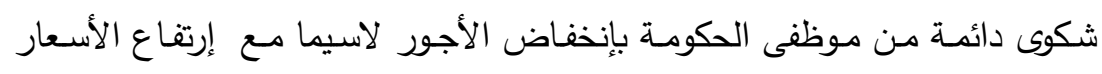

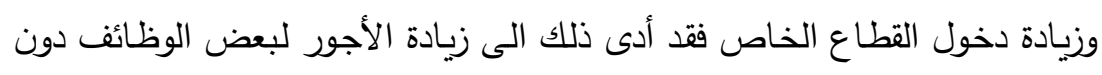

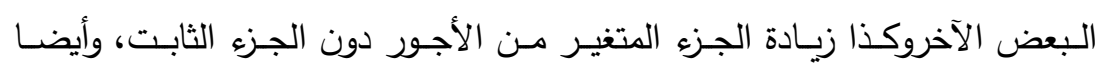

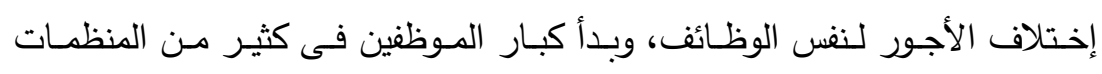

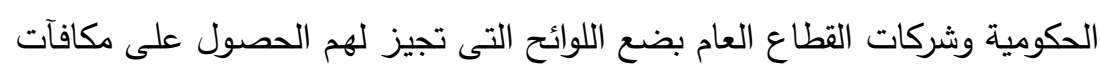
ضخمة ليس لها علاقة بالإنتاج أوالأداء. 
ويرى الباحث أن تلك المشكلة من أهم المشاكل لعدة أسباب، الأول أن

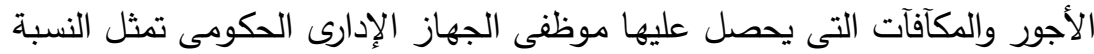

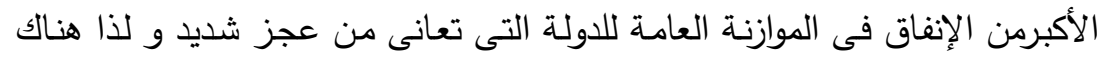

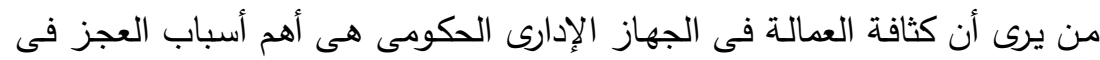

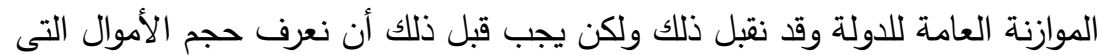
يحصل عليها جميع من يعمل في المنظمات الحكوميـة وعلى رأسهم المديرين، والسبب الثانى إرتفاع الأسعار الى مستويات غير مسبوقة لاسيما بعد تخفيض قيمة السئة

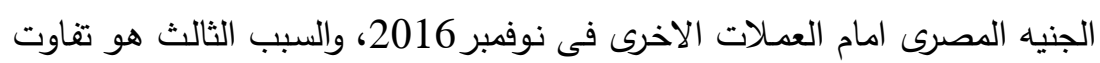
الأجور والدكافآت حتى لنفس الوظائف، ولذا فإن هناك ألكات أصوات تخرج من آن لآخر تنادى بوضع حد أقصى للاخل فى تلك المنظمات.

والباحث يقترح أن تقوم الدولـة بعمل برنـامج كمبيوتر لـن يكلف كثيراً

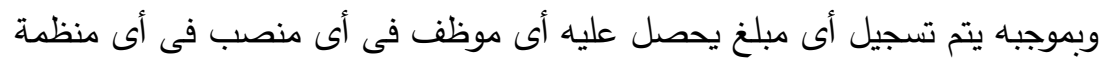
حكومية أو شركة قطاع عام مع كتابة مسمى هذا المبلغ سواء أجر أومكافآة أو غيره

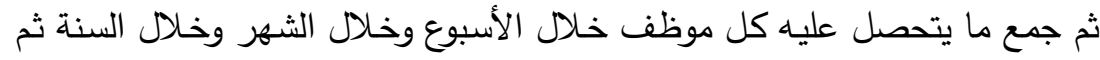

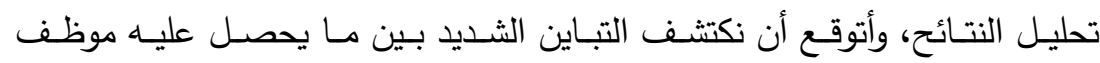
وآخردون أن يرتبط ذلك بالأداء والإنتاج وأن نكتثف صور كثيرة من الخلل وتكاليف

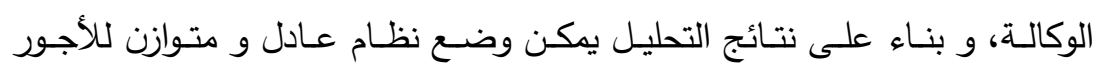
والمكافآت وحد أقصى للدخل.

سابعاً/تكلفة التسيب 


\section{Lenience}

هذا النوع من تكاليف الوكالة لمُيذكر فى أدب الوكالة بالتطبيق على التى

الشركات المساهمة التى تمثل القطاع الخاص، ولكن الباحث يعتقد أن مشكلة التسيب وما يترتب عليها من إهدار للوقت والموارد المادية والإنتاجية تعتبر من أهم

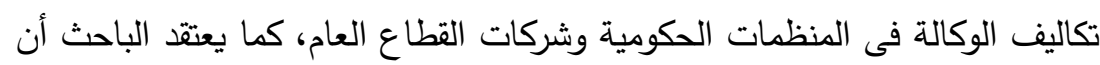
هذا التسيب له علاقة وثيقة كسبب أو كنتيجة للأشكال الأخرى من تكاليف الوكالة ومشكلة تعيين المديرين غير المناسبين على الوجه الذى سبق ذكره.

هذا ويرجع التسيب فى المنظمات الحكومية لضعف الدور الرقابى للمديرين

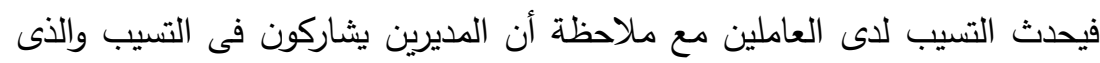

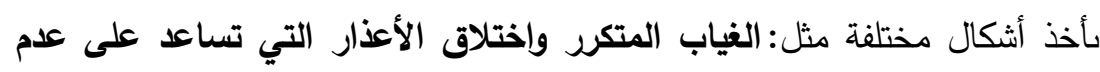

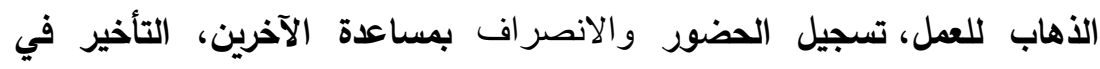
الحضور للعمل وعدم الالتزام بالوقت والخروج من العمل مبكراً دون انجاز أية أعمال، والاستئذان بثكل متكرر بحجة الظروف الخاصة، وعدم تطبيق الواجبات على الجميع وعدم الإهتمام بجودة الخدمات المقدمة للعملاء أو شكاوهم.

و يرى الباحث أن مشكلة التسيب وما يترتب عليها من تكاليف وإهدار

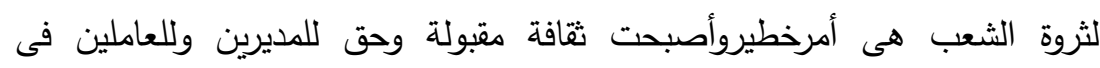

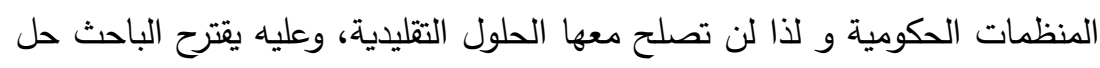
غير تقليدى بمساعدة القوات المسلحة، وذلك بإنشاء فرع للقوات المسلحة مكون من عسكريين لديهم بعض المعرفة و المهارات الإدارية والفنية بحسب طبيعة نشاط لئاء

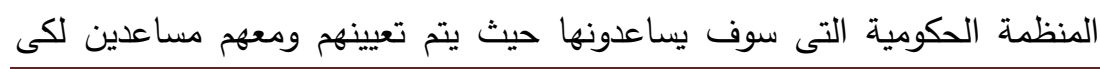




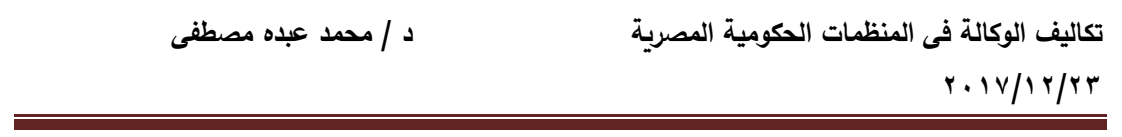

يطبقوا الإنضباط Discipline وإن كان بدرجة أقل مما هو فى الحياة العسكرية، وذلك كما هو مطبق فى عدد من المنظمات العسكرية التى تخدم المدنيين ومنها مثلاً المستشفيات العسكرية، وذلك للتخلص من التسسيب وتكاليفه الثديدة.

\section{الخلاصة و التوصيات}

هذا البحث ينطلق من إفتراض مؤداه أن إفتراضـات نظريـة الوكالة تتطبق

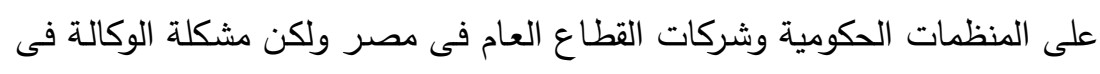


تلك المنظمـات أشــ وأكثر تعقيـأ منهـا فـى الشـركات المسـاهمة المملوكـة للقطـاع

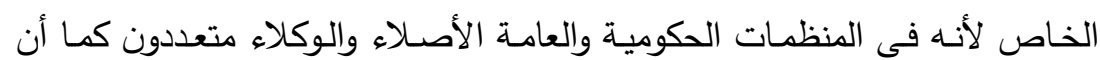

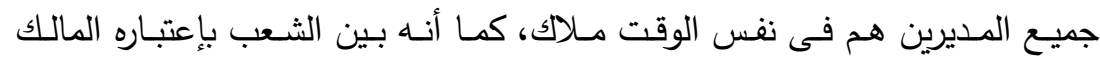

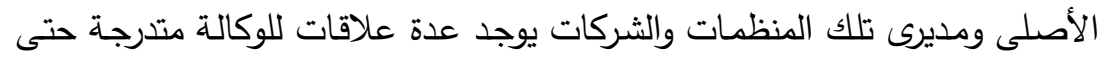
نصل الى المديرين الأعلى ممثلين فى الوزراء أوالمحافظين التابع لهم تلك المنظمات

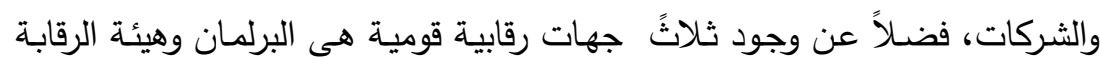
الإدارية والجهاز المركزى للمحاسبات.

هدف هذا البحث تحليل تكاليف الوكالة فى المنظمات الحكومية وشركات

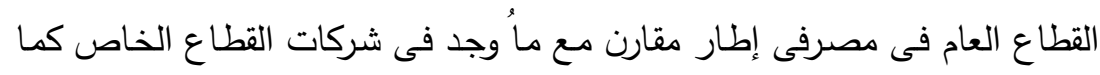

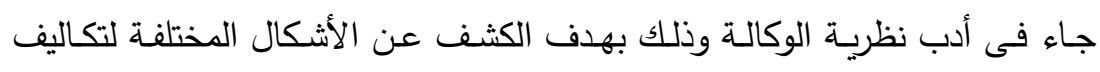

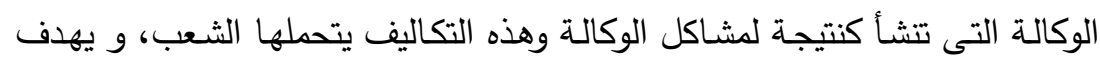

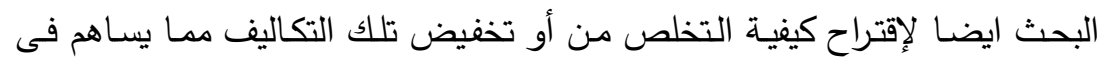

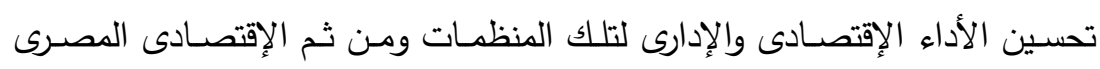

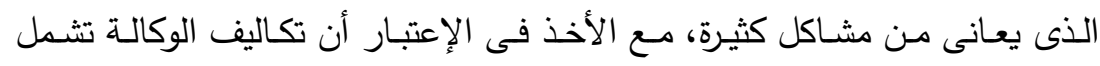

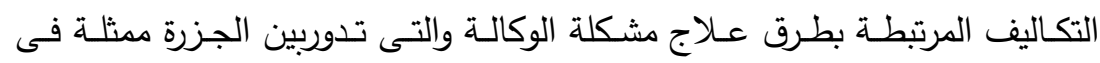
الحوافز والعصا ممثلة فى رقابة المديرين وعقابهم.

أثتبت الدراسة أن تكاليف الوكالة المترتبة على مشاكل الوكالة موجودة فى

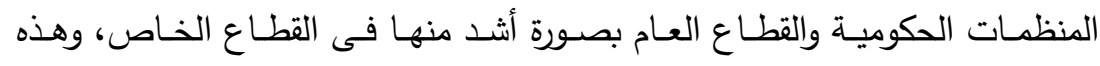

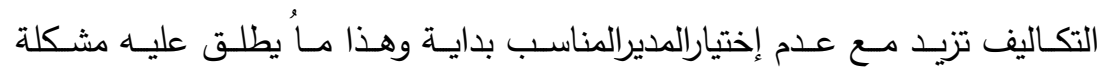

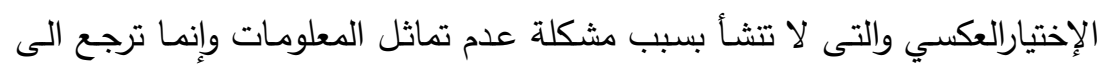




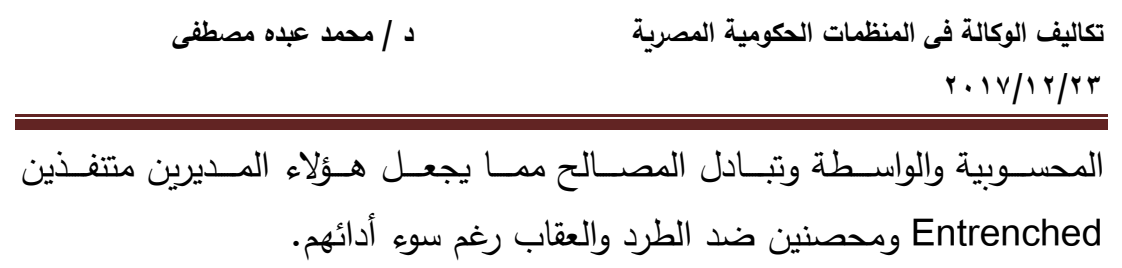

وقامت الدراسـة بتحليل الأشكال المختلفةالتالية لتكاليف الوكالة فى المنظمات

$$
\text { الحكومية وشركات القطاع العام فى مصر مع ضرب أمثلة: }
$$

ا. الإنفاق البذخى من جانب المديرين لتحقيق إثباع لهم دون أن يتحملوا

$$
\text { تكلفته و التى يتحملها الشعب دون أن تساهم فى زيادة ثروته. }
$$

r. تكاليف إستغلال المنصب من قبل المديرين لتحقيق مصالح شخصية.

r. عدم أداء الدديرين للواجبات المنوطة بهم بحسب نصوص عقود تعيينهم

$$
\text { لأنهم متتفدين و لا يتم حسابهح بحسب الأداء. }
$$

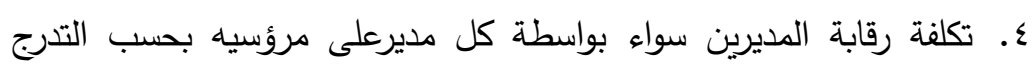

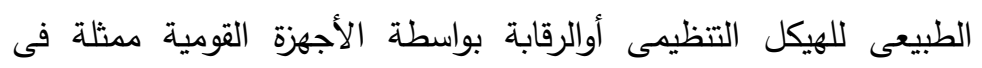

مجلس النواب وهيئة الرقابة الإدارية والجهازالمركزى للمحاسبات.

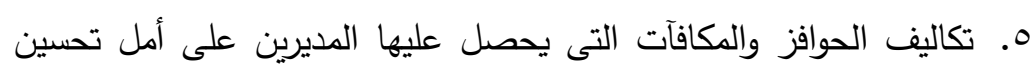

$$
\text { الأداء و زيادة ثروة الشعب. }
$$

7. تكلفة التسيب من جانب المديرين والعاملين فى المنظمات الحكومية و ودادو

$$
\text { شركات القطاع العام و الذى يؤدى لإهدار ثروة الشعب. }
$$

ولقد قدمت الدراسة أمثلة عملية لكل نوع من أنواع تكاليف الوكالة السابق ذكرها وكذا قدمت عدة توصيات خاصة بالتخلص من كل منها أوعلى الأقل تخفيضها وهذه 


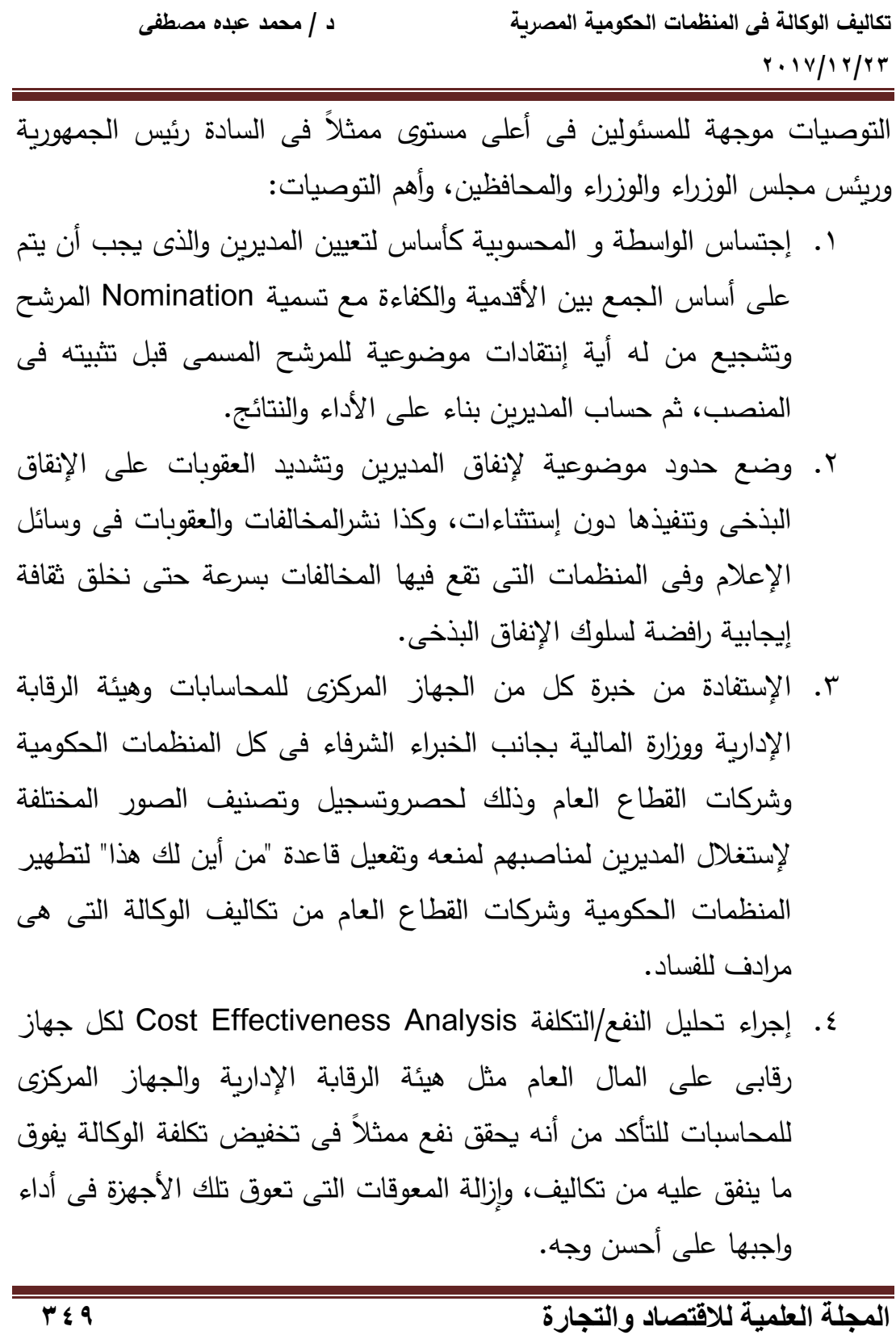




o

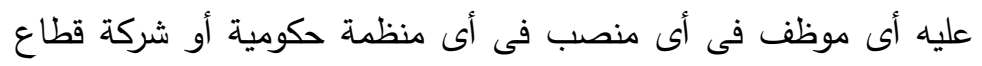

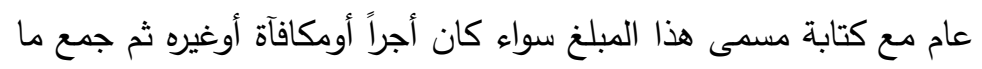
يتحصل عليه كل موظف خلال فترة معينة: أسبوع، شهرأوسنة ثم تحليل النتائح، لمعرفة الكثيرمن أوجه الخلل والفساد و علاجه ويتوقع الباحث

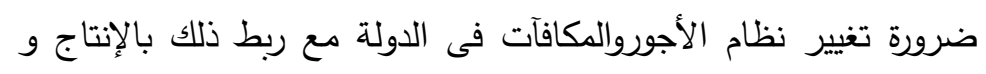

$$
\text { الأداء. }
$$

7. الإستعانة بالقوات المسلحة لفرض الإنضباط Discipline فى المنظمات الحكومية و شركات القطاع العام وإن كان بدرجة أقل مما هو في الإنيات الحياة

$$
\text { العسكرية. }
$$

كما أنناً نوصى البحوث المستقبلية بأن تقوم بدراسة كل نوع من تكاليف الوكالة

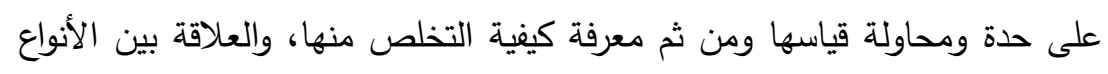

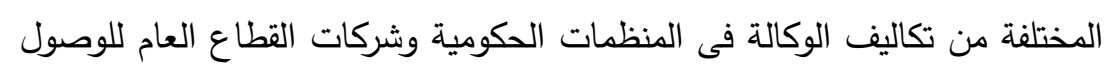
الى إصلاح إدارى وإقتصادى حقيقى وفعال لتلك المنظمات بما يساهم فى إصلاح

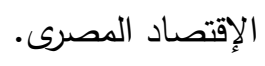

وأخيراً يرى الباحث أنه حتى تجد التوصيات السابق ذكرها طريقها للتنفيذ فإنه

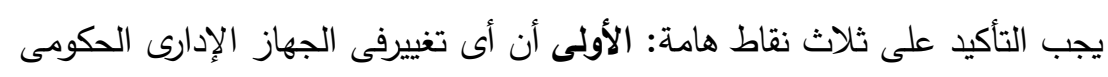

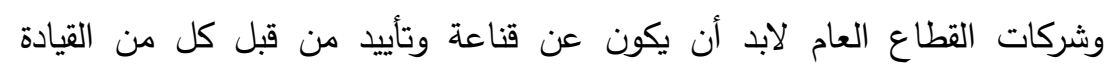

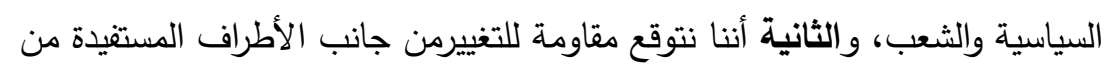

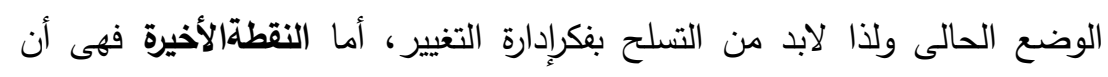




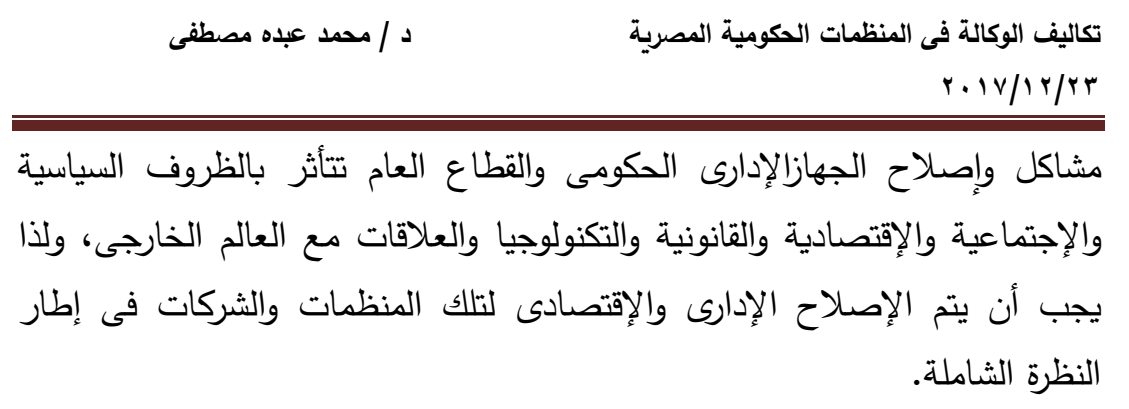

المراجح

المجلة العلمية للاقتصاد والتجارة 


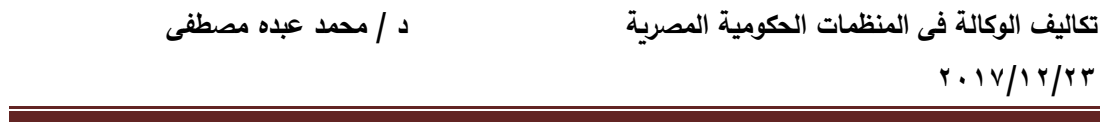

$$
\begin{aligned}
& \text { - - مصطفى، محمد2015a) (" النظريات الإقتصادية للمنشأة" ، المجلة العلمية } \\
& \text { للاقتصاد والإدارة، كلية التجارة - جامعة عين شمس، العدد الثانى. } \\
& \text { - مصطفى، محمد2015b) (" إمكانية تطبيق نظرية الوكالة على المنظمات } \\
& \text { الحكوميـة العامـة فـى مصر " ، المجلـة العلميـة للاقتصـاد والإدارة، كليـة التجارة - } \\
& \text { جامعة عين شمس، العدد الرابع. } \\
& \text { - مصطفى، محمد (2006) "تأثير بعض آليات حوكمة الثركات على الأداء : } \\
& \text { دراسة تطبيقية على مصر" مجلة كلية التجارة للبحوث العلمية" جامعة الأسكندرية }
\end{aligned}
$$

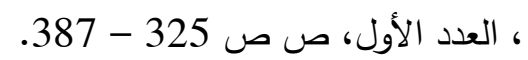

- Davis, J., F. Schoorman and L. Donaldson (1997) "Toward a Stewardship Theory of Management "Academy of Management Review, 22(1), PP. 20-47.

- Eisenhardt, K. (1989) "Agency theory: An assessment and review" Academy of Management Review, 14, PP. 57-74.

- Fama, E. (1980) "Agency problems and the theory of the firm" Journal of Political Economy, 88, PP. 288-307.

- Farinha, J. (2003) "Corporate Governance: A Survey of the Literature" SSRN working paper series no 470801.

- Fjeldstad, O. and Isaksen, J. (2008) "Anti-Corruption Reforms: Challenges, Effects and Limits of World Bank Support “, IEG Working Paper, World Bank, 2008/7.

- Jensen, M. (2003) "Paying People to Lie: The Truth about the Budgeting Process" European Financial Management, 9 (3), PP. 379-406.

- Jensen, M., and K. Murphy (1990) "Performance Pay and TopManagement Incentioves "Journal of Political Economy, Vol 98 (2), PP. 225-264. 


\begin{tabular}{|c|c|}
\hline دـ / محمد عده مصطفى & بكاليف الوكالة فى المنظمات الحكومية المصرية \\
\hline
\end{tabular}

- Jensen, M. And W. Meckling (1976) "Theory of the firm: managerial behavior, agency-costs, and Ownership Structure" Journal of Financial Economics, 3, PP. 305-60.

- Johnson, S., R. La Porta, F., Lopez-de-Silanes and A. Shleifer. (2000) "Tunneling" American Economic Review, 90(2):22-27.

- Linder, S. and N. Foss (2013) "Agency Theory" Working Paper SSRN at: www.ssrn.com (2255895).

- Locatelli, G., G., Mariani, T., Sainati and M. Greco (2017) "Corruption in public projects and megaprojects: there is an elephant in the room!", International Journal of Project Management, 35, PP. 252-268.

- Niskanen, W., (1971) "Bureaucracy and Representative Government", Chicago: Aldine.

- Ross, S. (1973) "The economic theory of agency: The principal's problem" American Economic Review, 63, PP.134139.

- Shleifer, A., and R. Vishny (1997) "A Survey of corporate governance" Journal of Finance, 52, PP. 737-783.

- Williamson, O. (1964), "The Economics of Discretionary Behavior: Managerial Objectives in a Theory of the Firm" Englewood Cliffs, NJ: PrenticeHall. 